\title{
Selective attention to Stroop dimensions: Effects of baseline discriminability, response mode, and practice
}

\author{
ROBERT D. MELARA and JEFFREY R. W. MOUNTS \\ Purdue University, West Lafayette, Indiana
}

\begin{abstract}
The framework of dimensional interaction was used to test the hypothesis that the Stroop effect is partially rooted in mismatches in baseline discriminability, with stimulus differences along the word dimension typically exceeding stimulus differences along the color dimension. Subjects made speeded classifications, with either keypresses or vocalizations, of either words or colors. Stroop congruity and Garner interference were measured under conditions in which discriminabilities were (1) matched (Experiments 1 and 4), (2) mismatched in favor of colors (Experiment 2), or (3) mismatched in favor of words (Experiment 3). When matched, colors and words appeared separable, with small interactive effects being reduced or eliminated through practice. When mismatched, asymmetric Stroop and Garner effects emerged, with the more discriminable dimension disrupting classification of the less discriminable dimension. Asymmetric effects were obtained in both response modes, and were not alleviated by practice. We conclude that (1) the Stroop effect is an optional effect, and (2) unequal discriminability causes a mandatory failure of selective attention.
\end{abstract}

In his comprehensive review, MacLeod (1991) noted that, since the seminal paper by Stroop in 1935 , over 700 articles have explored some aspect of the phenomenon that Stroop discovered. Stroop's study is especially intriguing because of the peculiar asymmetry that characterized his subjects' performance: When they read color words printed in various colors, irrelevant color had no effect on performance; however, when they named the colors of these words, the irrelevant words hindered performance significantly. This asymmetry is known universally as the Stroop effect. Much is now known about how this effect relates to a host of experimental variables. Some of these relations are discussed below. Despite an enormous amount of empirical study, however, the wider theoretical implications of Stroop's work have largely eluded researchers. In the present study, we view the Stroop effect in a different light-namely, that of research and theory on dimensional interaction. This approach permits us to fit the Stroop effect comfortably into the broader framework of what factors cause selective attention to succeed or fail. Our efforts yield new insights into the nature of the Stroop effect, on the one hand, and the nature of selective attention, on the other.

\section{Selective Attention and Dimensional Interaction}

The questions of whether and how humans integrate the separate sources of information in their environment have

This research was supported by National Institutes of Health Grant NS28617 to R.D.M. We thank Margaret Jean Intons-Peterson, Colin MacLeod, John Flowers, and Gregory Lockhead for their detailed comments and suggestions about an earlier draft. Address all correspondence to R. D. Melara, Department of Psychological Sciences, Purdue University, West Lafayette, IN 47907. enjoyed considerable research focus within cognitive psychology. One reason is that these issues have great bearing on the nature of many fundamental cognitive processes, including those in perception (see, e.g., Ashby \& Townsend, 1986; Garner, 1974a, 1974b; Lockhead, 1972, 1979), attention (e.g., Logan, 1980, 1988; Treisman \& Gelade, 1980), memory (e.g., Jacoby \& Dallas, 1981; Kirsner \& Dunn, 1985; Melara \& Nairne, 1991), and cognitive development (e.g., Kemler, 1983; Shepp, 1989 ; L. B. Smith \& Kemler, 1977, 1978). An influential method for studying information integration is speeded classification (Garner, 1974b): Observers are asked to make judgments about values from one dimension of experience-for example, whether shapes are squares or circles-while ignoring irrelevant variation on a second dimension of experience-for example, whether the shape's color is red or green. The ability to attend selectively is measured by comparing performance in a baseline condition, in which the irrelevant dimension is held constant (e.g., all shapes are red), with performance in a filtering condition, in which the two dimensions are varied orthogonally. If the speed and accuracy of performance in filtering equals that at baseline, selective attention is perfect: Subjects can focus on one dimension (shape) without distraction from irrelevant variation on the other dimension (color). Conversely, if filtering performance is worse than baseline-that is, if observers suffer significant Garner interference in classificationwe conclude that selective attention has faltered to some degree. Pairs of dimensions that lead to substantial Garner interference are called interacting dimensions. Pairs of dimensions associated with negligible Garner interference are called separable dimensions. Color and shape, in 
the example given above, exemplify a pair of separable dimensions.

From the standpoint of research on dimensional interaction, the dimensions of color and word studied by Stroop (1935) appear to represent a special case. When his subjects were classifying words, their ability to attend selectively was good: In comparison with performance on a baseline condition in which all words were printed in black, Stroop's subjects were not harmed in their reading performance by irrelevant changes in color. This suggests that the dimension of word is separable from the dimension of color. On the other hand, when the subjects were classifying colors, selective attention failed: Compared with the results of a baseline condition in which subjects named the color of squares, performance at naming the color of color words was poor. This suggests that color interacts with word.

What accounts for the performance asymmetry found with Stroop's dimensions? The use of speeded classification suggests one possible explanation. Traditionally, when one is testing the separability of a pair of dimensions, the baseline discriminability of the dimensions is matched. Discriminability refers to the psychological difference separating two stimulus values along a dimension, measured from identification performance as the values alternate randomly from trial to trial. Discriminability is matched when the values along one dimension are as different psychologically as the values along another dimension. For example, the dimensions of color and word are matched when the speed and accuracy to discriminate, say, RED in red from RED in green (i.e., a baseline color judgment) equals the speed and accuracy to discriminate, say, RED in red from GREEN in red (i.e., a baseline word judgment). Stroop effects might be caused in part by an asymmetry in the baseline discriminability of the dimensions of color and word.

The classic study on effects of baseline discriminability was conducted by Garner and Felfoldy (1970). Among the stimuli that they investigated were circles that could vary in size and diameter angle. In one experiment, the speed at baseline to make size judgments was equated with the speed at baseline to make angle judgments. Under these conditions, Garner and Felfoldy found that subjects could attend selectively to either of the dimensions, free from the potential influences of the other dimension. In a later experiment, the authors purposely altered discriminability, making angle discrimination more difficult. Under these conditions, Garner and Felfoldy found an asymmetry of interference: Angle judgments were slowed by orthogonal variation in size, but size judgments were unaffected by changes in angle. Hence, by unequating baseline speeds, an asymmetry occurred in selective attention between otherwise separable dimensions: The more discriminable dimension caused a failure of selective attention to the less discriminable dimension, but not vice versa.

Garner and Felfoldy's (1970) findings have several implications (see also Garner, 1983), three of which are men- tioned here. First, the findings suggest that failure to attend selectively is due mainly to variation (i.e., trial-totrial alternations) in irrelevant information, and not merely to its presence (see Lockhead, 1992). In any everyday task of selective attention (e.g., typing on a computer), sources of irrelevant information abound (e.g., the color of the wall, the presence of extra chairs in the room, the shape of the computer screen). But the mere presence of this information does not necessarily hold any consequences for selective attention, especially if it remains constant. According to the logic used in studying dimensional interactions, true harm to selective attention is relegated to orthogonal changes in the irrelevant information. As we shall see, this logic contrasts with that used traditionally in characterizing Stroop effects.

Second, Garner and Felfoldy's (1970) findings suggest that the actual psychological difference separating values along the irrelevant dimension dictates how extensively selective attention fails, regardless of whether dimensions are interacting or separable. Thus, interactive processing is controlled by both the presence and the relative magnitude of dimensional variation. At one extreme, variation in dimension $A$ may cause no Garner interference in dimension $B$, even between dimensions that otherwise interact, if dimension $A$ 's variation is psychologically minuscule relative to dimension $B$. In the limiting case, changes along the irrelevant dimension might not be noticeable enough to engender interfering effects. At the other extreme, variation in dimension $A$ may cause Garner interference in dimension $B$, even between dimensions that are otherwise separable, if dimension $A$ 's variation is psychologically huge relative to dimension $B$. In the limit, environmental variation could be so extreme that performance in even the most autonomous selective attention task is disrupted. These cases underscore the importance of assessing baseline discriminability when one is evaluating how humans process two sources of information, and when one is predicting whether selective attention will succeed or fail.

Finally, Garner and Felfoldy's (1970) findings are potentially useful in understanding the Stroop asymmetry. Stroop (1935) found that, when the irrelevant dimension was held constant, subjects were much slower to name colors (of squares) than to read color words (printed in black). Moreover, when the irrelevant dimension was varied, he found that the more discriminable dimension, word, affected judgments about the less discriminable dimension, color, but not vice versa. If we reformulate Stroop's study as a test of dimensional interaction, one possible cause of the asymmetry is a mismatch in baseline discriminability between what might conceivably be separable dimensions.

\section{Stroop and Garner Effects}

Our primary goal in the present study is to explore how asymmetric failures of selective attention to the Stroop dimensions of color and word may be rooted, at least in part, in mismatches in the discriminability of these dimen- 
sions at baseline. As mentioned above, the possible role of baseline discriminability derives from research measuring Garner interference in speeded classification. Garner interference is considered by many to be a particularly sensitive measure of failures in selective attention. Of course, the Stroop effect also indicates that selective attention has failed. To the best of our knowledge, however, only one study (described below) has ever measured both Garner interference and the Stroop effect on the dimensions of color and word. Thus, our understanding of the relations between these two indices is incomplete. Are they interchangeable? Are they affected similarly by stimulus and response manipulations? We address these questions in the present study.

To study Stroop effects, we use a variant of Stroop's (1935) paradigm. In his original study, Stroop ensured that the word conflicted with its color on all experimental trials; he compared performance on experimental trials with performance on baseline trials. In the present study, we vary the dimensions of color and word orthogonally: on half the trials, the word corresponds to its color, and on half, it conflicts. Of course, this situation is exactly the filtering condition used in speeded classification. We measure Stroop congruity both in filtering and at baseline ${ }^{1}$ which is defined as a difference in classification reaction time (RT) between trials in which the color and the word correspond (i.e., congruent trials) and trials in which the color and the word conflict (i.e., incongruent trials). Congruity measures have frequently substituted for Stroop's original measure (see, e.g., Nealis, 1973; Schulz, 1979; Sichel \& Chandler, 1969; Simon \& Berbaum, 1990; Simon \& Sudalaimuthu, 1979; G. J. W. Smith, 1970) and have been used in tests of many other dimensions whose values have a correspondence quality (e.g., Clark \& Brownell, 1976; Melara, 1989; Redding \& Tharp, 1981; Walker \& S. Smith, 1984).

Measuring congruity allows us to assess Stroop effects under the same experimental context that is used to assess Garner interference. There is an interesting conceptual relation between these two measures. As noted by Pomerantz (1983; see also Pomerantz, 1986), Garner interference suggests an appreciation in the perceiver of dimensional change (i.e., that the irrelevant dimension is varying), whereas effects of congruity suggest an appreciation of the kind of dimensional change (i.e., that the value on the irrelevant dimension corresponds or conflicts with the value on the relevant dimension). Consequently, Pomerantz, Pristach, and Carson (1989) maintain that congruity effects should imply Garner interference because, logically, the perceiver cannot experience "kind of change" without also experiencing "change." In the present study, we examine whether effects of congruity caused by variation in Stroop dimensions always appear in the presence of Garner interference.

\section{Relation to Speed-of-Processing Models: Previous Findings}

The idea that Stroop asymmetry may be partially due to mismatches in discriminability is related to at least one popular account of the Stroop effect. Called "speed-ofprocessing models" by MacLeod (1991; also called "horse-race models" by Dunbar \& MacLeod, 1984), this view states that the Stroop asymmetry is attributable to the inherently faster speed with which humans process and respond to words as opposed to colors (Dyer, 1973; Fraisse, 1969; Keele, 1972; Morton \& Chambers, 1973; Posner \& Snyder, 1975; Treisman, 1969; see MacLeod, 1991 , for a review). The idea is that asymmetry in the speed of processing leads to slowed color naming because of a competition at a single-channel response stage between responses to words, which are available first, and responses to colors, which are the basis of the classification. This view shares with the concept of baseline discriminability the conviction that the asymmetry in performance is rooted in an asymmetry in processing.

Yet there exists at least one crucial difference between the two approaches: Speed-of-processing models assume that if an irrelevant aspect of a stimulus (i.e., word identity) is processed faster than the relevant aspect (i.e., color identity), interference will result. A similar assumption appears in competing Stroop models, which propose that irrelevant attributes are processed more strongly than relevant attributes (e.g., Cohen, Dunbar, \& McClelland, 1990; MacLeod \& Dunbar, 1988). Both kinds of models view stimulus attributes more as discrete features than as values on psychologically meaningful continua. Hence, in contrast to our approach, such models do not consider either (1) the relative discriminability of the dimensions or (2) the trial-to-trial changes in stimuli as fundamental to the Stroop effect.

Consider the following situation: A subject making color classifications responds "red" to RED printed in green. Speed-of-processing models ascribe this error to fast processing of the word attribute (i.e., RED) relative to the color attribute (i.e., green). In other words, these models emphasize the relative speed with which individual attributes are identified on different dimensions, and ignore the relative speed with which multiple values are discriminated on a single dimension. Thus, taken at face value, this view implies that, for typical values on Stroop dimensions, Garner baseline tasks should yield overall speed and congruity effects equivalent to those of filtering tasks, because (1) in both types of tasks, half the trials are congruent and half are incongruent and (2) the stimulus attributes tested are shared between tasks. This idea seems improbable, to the extent that subjects perform Garner baseline trials at the level of traditional Stroop baseline trials. Still, analyses performed in this study assess for the first time the separate contributions of attribute identity (i.e., speed or strength to identify features), a central component to current models of the Stroop effect, versus dimensional discriminability, a construct absent from most characterizations of the Stroop effect.

Despite differences with our approach, it is useful to review previous tests of speed-of-processing models, because results from these tests bear on the role of baseline discriminability in the Stroop effect. In one series of experiments, performed by Glaser and Glaser (1982), sub- 
jects received color information at one of several intervals prior to receiving word information. The logic of the manipulation was this: Delaying presentation of words enhances the likelihood that color information undergoes response processing first. Glaser and Glaser also included a condition in which the word preceded the color in color naming; in still other conditions, the irrelevant stimulus actually followed the relevant stimulus. The investigators compared RTs on baseline trials (e.g., a series of vertical bars in the color naming task) with RTs on congruent trials (i.e., the color corresponded to the word) and on incongruent trials (i.e., the color had a name different from the word). They found a Stroop asymmetry in each condition: Color naming was affected by irrelevant words (i.e., congruent RTs were faster than baseline RTs; incongruent RTs were slower than baseline RTs), but word reading was not affected by irrelevant colors (i.e., baseline, congruent, and incongruent RTs were equivalent).

Word reading was unaffected even when irrelevant colors preceded words by as much as $400 \mathrm{msec}$, suggesting to Glaser and Glaser (1982) that the Stroop effect is not due to differences in arrival at a response stage. Importantly, though, even at the $400-\mathrm{msec}$ lag, baseline speeds with colors were approximately $100 \mathrm{msec}$ slower than baseline speeds with words. Thus, the delay manipulation apparently had no effect on baseline discriminabilities, which were still in favor of the word dimension, and so might reasonably have accounted for the Stroop asymmetry. In a later experiment, Glaser and Glaser obtained substantial overlap, albeit serendipitously, in RTs to color naming and word reading. Perhaps as a partial consequence, dimensional influences were now more nearly symmetrical.

A more direct test of baseline discriminability was undertaken by Gumenik and Glass (1970). They varied the baseline speed of identifying words and colors by presenting Stroop stimuli when a mask either was or was not superimposed. In the absence of the mask, word reading was more efficient than color naming, and the usual Stroop asymmetry appeared. However, with the mask superimposed, baseline word reading was slower than baseline color naming. This sharply reduced the effect of words on color naming. Moreover, in contrast to the usual Stroop asymmetry, a reverse Stroop effect emerged, in which the colors significantly disrupted the subjects' ability to read color words. These findings fit the idea that the Stroop effect does not reflect intrinsic characteristics of colors and words, but can be reversed by changing baseline discriminabilities. Unfortunately, Gumenik and Glass's investigation has been criticized because their stimuli were not controlled for differences in legibility, and because their subjects were required to practice color naming before performing word reading trials (see Dunbar \& MacLeod, 1984; Dyer, 1973; Dyer \& Severance, 1972). So their study does not categorically establish a role for baseline discriminabilities.

Dunbar and MacLeod (1984) varied baseline discriminability by transforming color words backward or upside-down and backward. When mixed with noncolor control words, this manipulation effectively slowed reading relative to color naming. The results are difficult to interpret, however, because the investigators found a reverse Stroop effect when the words were both upsidedown and backward, but not when the words were merely backward, despite the fact that the latter condition yielded slower reaction times (RTs) on control trials. Dunbar and MacLeod were unable to explain this anomaly. Still, it is significant that in their study the reverse Stroop effect never appeared in the absence of the usual Stroop effect. This implies, in contrast to Gumenik and Glass's (1970) study, that the Stroop effect may be ubiquitous despite manipulations of baseline discriminability (see also Clark \& Brownell, 1976).

This conclusion conflicts, though, with research by Palef and Olson (1975). They tested keypress responses to the dimensions of word ("above" or "below") and position (the word appeared above or below a central asterisk). Palef and Olson found that when position was made more discriminable than word (or, in their terms, when there was faster position processing), position changes caused congruity effects in word judgments, but words did not affect position judgments. Of course, this is opposite to the typical Stroop pattern. Interestingly, when position was made less discriminable than words, symmetrical congruity effects obtained. Palef and Olson claimed here, though, that because speeds of discriminating positions improved dramatically with practice, psychologically the two dimensions were matched in speed of processing.

Palef and Olson's (1975) results certainly imply that asymmetries in congruity may be occasioned by a mismatch in baseline discriminability. Of course, it is not obvious whether their results relate to processing of Stroop dimensions (i.e., color and word), especially when subjects make vocal rather than manual responses (see below). What we believe to be most important about Palef and Olson's study is its suggestions, maybe not recognized by the authors themselves, that (1) congruity effects are rooted in trial-to-trial variation along the irrelevant dimension and (2) Stroop-like asymmetries are rooted in unequal degrees of change between the relevant and irrelevant dimensions. In the present study, we evaluate these ideas directly.

\section{Other Factors Underlying the Stroop Effect}

Up to this point, we have been discussing baseline discriminability as if it might be the only cause of the Stroop asymmetry. But several other factors have been clearly implicated in the Stroop effect. As a consequence, the issue of baseline discriminability cannot be examined in isolation-as has been the predominant approach in previous research-but must be evaluated in the context of these other factors. It is possible to consider these factors as affecting subjects' general ability to attend selectively to a source of information in their environment. Two factors are especially prominent in this regard: 
(1) the role of response modality and (2) the effects of experience. We discuss each issue in turn.

Stimulus-response compatibility. Students of the Stroop effect have long recognized the importance of vocal responding to the performance asymmetry (see MacLeod, 1991 ; cf. Proctor \& Reeve, 1990). Although the Stroop effect does obtain with manual responding (e.g., keypresses), it is larger and more consistent when subjects respond orally. One explanation, suggested by Virzi and Egeth (1985), is that interference arises from the need to translate values on the relevant dimension into the coding scheme of the response system. If the dimensions are words and colors, and the response system is verbal, color values require translation, but word values do not because they are already coded semantically. Hence, color naming should show interference, but word naming should not, the typical Stroop asymmetry.

McClain (1983) performed an illustrative study. Subjects identified values on one of two Stroop analogue dimensions: pitch (high or low) or word ("high" or "low"), which were varied orthogonally. Responses were made by saying "high" or "low," by humming at a high or low pitch, or by pressing keys designated as "high" or "low." The idea was that the spoken response was more compatible with the word dimension, the humming response more compatible with the pitch dimension, and the keypress response equally compatible with both dimensions. McClain found that with spoken responding, only pitch judgments displayed an effect of congruity, and that with humming, only word judgments displayed an effect of congruity. These results indicate a large role for response compatibility in causing effects of congruity. Unfortunately, McClain did not report individual task speeds, so we cannot assess whether baseline discriminabilities were matched. In the present study, we will see that baseline discriminability is related intimately to the response mode. Interestingly, McClain found that keypress responses led to the usual Stroop asymmetry: Congruity effects obtained only with the nonword dimension. This suggests that stimulus-response compatibility is not sufficient by itself to explain the Stroop effect (see also Flowers, Warner, \& Polansky, 1979).

Practice. Speeded classification is a relatively simple attention task. Nonetheless, for optimal performance, subjects must coordinate a number of separate activities, including (1) concentrating on the relevant dimension, (2) mapping the stimuli onto appropriate responses efficiently, and (3) determining decision criteria that maximize speed yet minimize errors. Reaching a stable level in an attention task thus necessitates some amount of experience at the task. One might expect that to the extent that subjects have not attained stable performance-for example, to the extent that task speeds have not reached asymptotic levels-there exists a higher probability of intrusion from the irrelevant dimension. It is possible, therefore, that the Stroop effect is highly dependent on practice at the task (cf. MacLeod \& Dunbar, 1988).

Melara and Marks (1990c, Experiment 6) evaluated how practice at classifying Stroop stimuli affects Garner interference and effects of congruity. The words were WHITE or BLACK printed in white or black. Subjects were tested in 15 blocks of 96 trials, in each block alternating between a baseline task and a filtering task. Only color classifications and keypress responses were tested. The results are shown in Figure 1: Garner interference is depicted in panel A; Stroop congruity effects are shown in panel B. As one can see, Melara and Marks found that both the Garner and the Stroop measures were sizable in magnitude during early blocks of trials, but both effects diminished with exposure, albeit not at the same rate. The results imply that interference effects with Stroop stimuli can quickly be brought under subjects' control, suggesting that Stroop dimensions might best be considered separable dimensions.

Several problems exist with Melara and Marks's (1990c) experiment, however, that preclude their conclusions. First, they measured only color discrimination, so that information about possible differences in discriminabil-
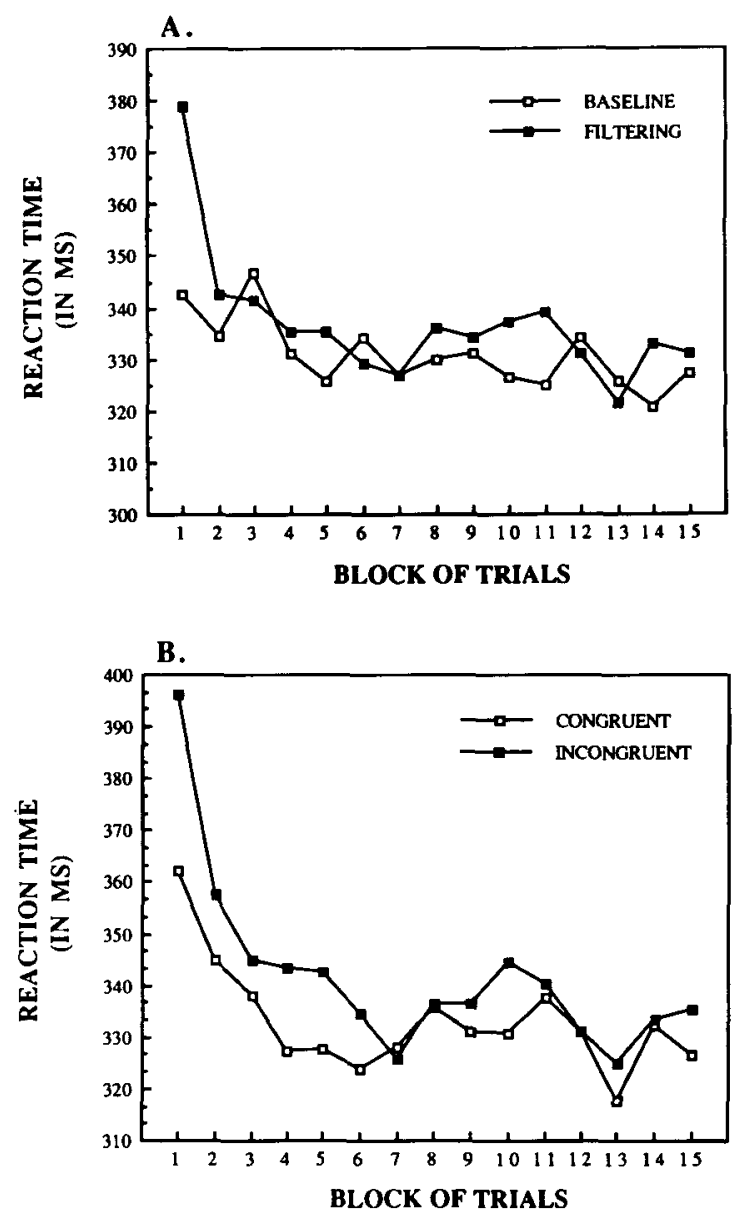

Figure 1. Summary of performance in color classification of the Stroop dimensions of color (white, black) and color word (WHTE, BLACK), as tested by Melara and Marks (1990c), in 15 blocks of 96 trials. (A) Average RT performance (in milliseconds) by block in baseline and filtering trials. (B) Average RT performance (in milliseconds) by block in congruent and incongruent filtering trials. 
ity between the two dimensions was unavailable. Second, they tested only two colors-white and black-over many trials; hence, it is possible that semantic satiation and not subject control underlies the shrinking effects. Finally, they used a manual response-keypressing-instead of Stroop's original vocal response.

These difficulties are compounded by results from previous investigations. For example, regarding semantic satiation, Reisberg, Baron, and Kemler (1980) found that reductions in interference from classification practice do not transfer well from one set of Stroop-like stimuli to another. Regarding response mode, Flowers and Stoup (1977), in an elegant series of experiments, demonstrated that continued exposure to Stroop stimuli reduces interference when the response mode is manual but, as Stroop (1935) himself showed, does not reduce interference when the response mode is oral. In general, previous findings dictate a more sophisticated analysis of the roles of practice, response mode, and baseline discriminability in the occurrence of the Stroop effect. This is the focus of the present study.

\section{The Present Experiments}

In this research, we consider the Stroop effect to be a problem of selective attention. We believe that various factors can cause selective attention to fail, and paramount among these is how well matched in discriminability one dimension is to a second, irrelevant dimension. Selective attention is more likely to fail when changes are psychologically larger along the irrelevant dimension than they are along the relevant dimension. Moreover, selective attention may be perfect when the discriminability of values on the two dimensions is equated; such success of selective attention indicates dimensional separability. Other factors, such as stimulus-response incompatibility and insufficient practice, may also cause selective attention to fail and, importantly, may interact statistically with discriminability.

We evaluated selective attention to Stroop dimensions in Garner's speeded classification paradigm. We manipulated baseline discriminability, response mode, and amount of practice in an effort to identify the importance of each factor to selective attention. Failure of selective attention was measured through Garner interference and Stroop congruity. We compared performance in filtering, where Stroop dimensions were varied orthogonally, with performance in a particular kind of baseline-namely, one in which the irrelevant dimension was held constant at one of two possible values. Although slightly different from the usual Stroop control condition, this baseline task permitted us to evaluate the separate roles of attribute identity (cf. speed-of-processing models) and dimensional variation in processing Stroop stimuli. It also allowed us to assess whether Stroop dimensions are described best as separable or as interacting dimensions. The results of our manipulations helped us reach a new understanding of the processing of Stroop dimensions, on the one hand, and the nature of selective attention, on the other.

\section{EXPERIMENTS 1c AND 1w}

The first pair of experiments was aimed at replicating the findings of Melara and Marks (1990c). Subjects were required to make keypress responses to either the color (Experiment 1c) or the word identity (Experiment $1 \mathrm{w}$ ) of Stroop stimuli over the course of 12 blocks of trials. To control for effects of semantic satiation (see Reisberg et al., 1980), values on the relevant and irrelevant dimensions were changed after 8 blocks. Irrelevant values were always within the current response set, to maximize possible interference effects (see Proctor, 1978). These experiments were preceded by extensive preliminary testing (with different subjects) to provide an approximate match between the baseline discriminabilities along the two dimensions. In this way, we were able to exact a stringent test of separability with Stroop stimuli.

\section{Method}

Subjects. Sixty-four subjects, 32 in each experiment $(9$ men, 23 women in Experiment 1c; 24 men, 8 women in Experiment 1w), each an undergraduate student at Purdue University, participated in partial fulfillment of a course requirement.

Stimuli and Apparatus. The stimuli were the words RED, GREEN, BLUE, and YELLOW, arranged in opponent pairs, and displayed in either matching (e.g., RED in red) or opponent mismatching (e.g., RED in green) color. The stimuli were generated in Times font by an Amiga 500 microcomputer and presented on a Commodore 1084A color monitor (P-22 phosphor), over a dark gray screen background. The colors were equated in Munsell value (brightness) and chroma (saturation). Hues corresponded to the following Munsell designations: red $=2.5 \mathrm{R}$; green $=2.5 \mathrm{G}$; yellow $=7.5 \mathrm{Y}$; blue $=10 \mathrm{~B}$. From pilot testing, it was determined that, to equate speeds of color and word discrimination, RED and GREEN needed to subtend $.57^{\circ}$ of visual angle in height (in width, RED $=.95^{\circ}$; GREEN $=1.43^{\circ}$ ), whereas BLUE and YELLOW needed to subtend $.86^{\circ}$ of visual angle (in width, BLUE $=1.43^{\circ}$; YELLOW $=2.10^{\circ}$ ). The stimuli were response terminated.

Procedure. The subjects were tested individually in a dimly lit room after successfully undergoing a test for color deficiency. The subjects in Experiment 1c classified colors, ignoring variation in words. The subjects in Experiment $1 \mathrm{w}$ classified words, ignoring color changes. In each experiment, half the subjects began with the red-green opponent pair, and half with the blue-yellow pair. All subjects were switched to the other pair, following 8 blocks of 96 trials.

Within each block, the subjects classified the colors in 48 baseline trials followed or preceded by 48 filtering trials. In the baseline tasks, the relevant dimension took on one of its two values (e.g., red or green) on each trial, but the irrelevant dimension was held constant at one of its values (e.g., RED) throughout the 48 trials. The particular value held constant was alternated between blocks. In the filtering tasks, both the relevant and the irrelevant dimensions could, on each trial, take on either of their two values (i.e., one of the four color/word stimulus combinations). The two (baseline) or four (filtering) stimuli in each condition appeared an equal number of times across trials. The subjects alternated between baseline and filtering for 12 blocks, with half the subjects beginning with the baseline condition and half beginning with the filtering condition. Within each task, the stimuli appeared randomly.

The subjects were instructed to attend to the relevant dimension and to attempt to ignore the irrelevant dimension. Classifications were made by pressing one of two keys on a dual-key Naksha mouse; key assignment was counterbalanced across subjects. RTs were mea- 
sured at millisecond accuracy with a hardware timer (Wright, 1986) The subjects were encouraged to respond quickly, but accurately. Trials containing latencies that exceeded $1,500 \mathrm{msec}$ were repeated later in the task. Tasks performed at less than $90 \%$ accuracy were repeated immediately. Following each set of 48 trials, the subjects were shown their average speed and accuracy. The entire experiment lasted approximately $50 \mathrm{~min}$.

\section{Results}

Overall performance. Average baseline performance was $356 \mathrm{msec}$ in Experiment $\mathrm{lc}$ and $357 \mathrm{msec}$ in Experiment $1 \mathrm{w}$. These baselines did not differ $[t(62)=.10$, n.s.], suggesting that the discriminabilities were matched. The subjects committed an average of .02 errors in Experiment $1 \mathrm{c}$, and .03 in Experiment $1 \mathrm{w}$. The correlation between speed and accuracy, computed in these and in other experiments in this study from averaged baseline and filtering performance in each block, was .34 in Experiment $1 \mathrm{c}$ and .14 in Experiment $1 \mathrm{w} .{ }^{2}$ This correlation suggests little evidence of a tradeoff between speed and accuracy in either experiment. In this and in succeeding experiments, we analyzed both speed and accuracy, although, because the former measure is generally more stable in speeded classification (see Melara \& Marks, 1990 c), our interpretations will emphasize RTs.
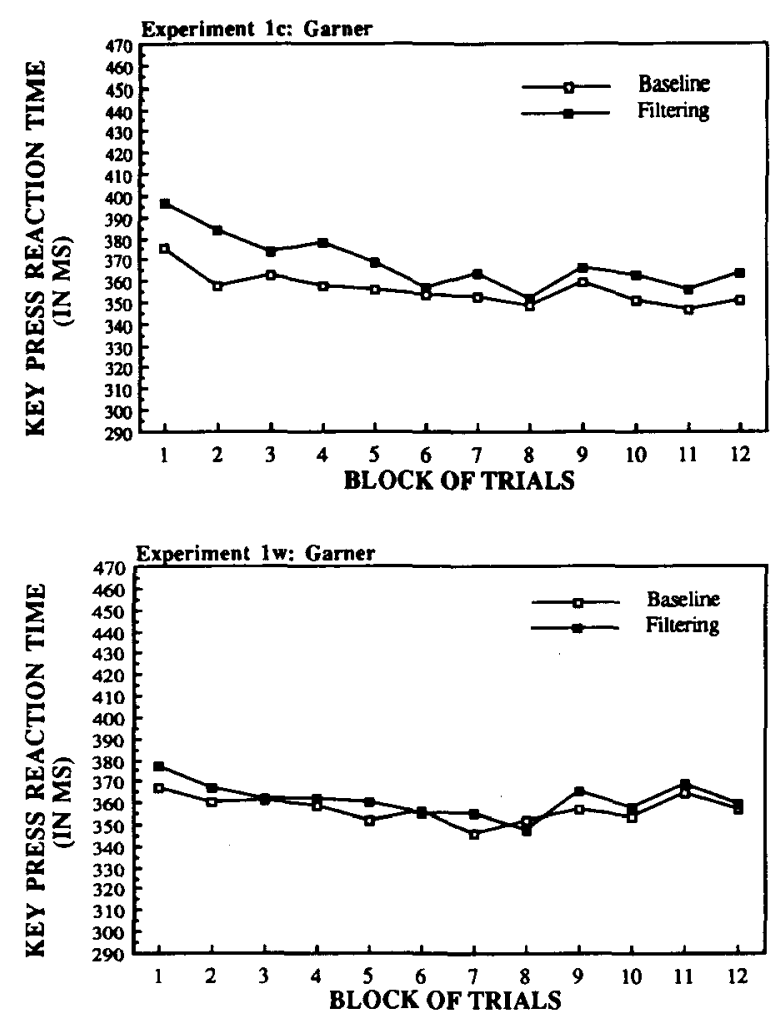

Figure 2. Summary of performance in baseline and filtering trials in each of 12 blocks of 96 trials with Stroop stimuli (i.e., the color words RED, GREEN, BLUE, or YELLOW printed in either matching or opponent mismatching color). Keypress responses were made either to the colors (top panel; Experiment 1c) or to the color words (bottom panel; Experiment 1w). The two dimensions were matched in baseline discriminability.
Garner analyses. Average RTs in baseline and filtering for each of the 12 blocks appear in the top panel (Experiment 1c) and bottom panel (Experiment 1w) of Figure 2. RTs were evaluated in an analysis of variance (ANOVA), with block ( 12 levels) and condition ( 2 levels) as factors. In these and succeeding analyses, RTs are collapsed across stimulus set. Whether subjects transferred from red/green to blue/yellow or the reverse led to equivalent results.

In Experiment 1c, there was a significant effect of block $\left[F(11,341)=4.20, M S_{\mathrm{e}}=1,523.83, p<.001\right]$, because subjects' overall speed improved from $386 \mathrm{msec}$ in the first block to $350 \mathrm{msec}$ by the eighth block. There was also a statistically significant effect of condition $\left[F(1,31)=27.89, M S_{\mathrm{e}}=1,076.96, p<.001\right]$, although the average difference between baseline and filtering trials was only $13 \mathrm{msec}$. The interaction between block and condition did not reach significance $[F(11,341)=1.20$, $M S_{\mathrm{c}}=664.53$, n.s.]. The same pattern appeared in the error analysis. An ANOVA of error rates revealed a significant effect of block $\left[F(11,341)=2.30, M S_{e}=.02\right.$, $p<.01$, with errors decreasing from .03 in Block 1 to .02 by Block 5 . There was also a significant effect of condition $\left[F(1,31)=10.16, M S_{\mathrm{e}}=.02, p<.01\right]$, with more errors occurring in filtering (.03) than at baseline (.02). There was no interaction between block and condition $\left[F(11,341)=.18, M S_{\mathrm{e}}=.02\right.$, n.s. $]$.

The overall magnitude of Garner interference (13 msec) was small; a $t$-test analysis of difference scores (filtering RT - baseline RT) in each block of trials in Experiment $1 \mathrm{c}$, using the Bonferroni correction (.05 criterion value), revealed that only in Blocks 2 and 4 did Garner interference differ significantly from zero. What is most revealing about Experiment 1, therefore, is that subjects enjoyed good selective attention from the start of the experiment. Nevertheless, to permit further insights, we next report a series of planned contrasts performed on the RT data, using pooled within-subjects effects to derive error terms (see Winer, 1971). We performed (and report) this series in each experiment of this study, on both the Garner measure and the Stroop measure. In each series of contrasts, the average of the first two blocks was compared with (1) the average of the last two blocks, (2) the average of Blocks 7 and 8 (i.e., the last two blocks before transfer), and (3) the average of Blocks 9 and 10 (i.e., the first two blocks after transfer).

In Experiment 1c, this series of contrasts $\left(M S_{\mathrm{e}}=\right.$ $1,329.06)$ indicated that Garner interference in Blocks 1 and $2(23 \mathrm{msec})$ was significantly greater than that in Blocks 7 and $8(6 \mathrm{msec})[F(1,341)=6.87, p<.01]$, Blocks 9 and $10(9 \mathrm{msec})[F(1,341)=5.00, p=.03]$, and Blocks 11 and $12(11 \mathrm{msec})[F(1,341)=3.75, p=$ $.05]$. Thus, by this analysis, a modest initial effect virtually disappeared with practice.

The pattern in Experiment 1w mimicked that of Experiment $1 \mathrm{c}$, although the effects were even weaker overall (see Figure 2). Statistically, there was an effect of block $\left[F(11,341)=2.61, M S_{\mathrm{e}}=1,023.04, p<.01\right]$, an effect of condition $\left[F(1,31)=12.63, M S_{\mathrm{e}}=310.45, p<\right.$ $.01]$, and no interaction between block and condition 
$\left[F(11,341)=.67, M S_{\mathrm{e}}=472.83, \mathrm{n} . \mathrm{s}.\right]$. In the error analyses, only the effect of block was reliable $[F(11,341)=$ $\left.3.20, M S_{\mathrm{e}}=.02, p<.001\right]$. On the average, we observed only 4 msec of Garner interference in word classification. Garner interference was small even in Blocks 1 and 2 (8 msec); consequently, these blocks did not differ from Blocks 7 and $8(2 \mathrm{msec})\left[F(1,341)=1.13, M S_{\mathrm{e}}=\right.$ 945.66, n.s.], Blocks 9 and $10(6 \mathrm{msec})[F(1,341)=.25$, n.s.], or Blocks 11 and $12(3 \mathrm{msec})[F(1,341)=.95$, n.s.]. Bonferroni-corrected $t$ tests indicated that Garner interference did not differ significantly from zero in any block of Experiment 1w. In general, Experiment 1 yielded little evidence of Garner interference, especially in comparison with other experiments in this study.

Stroop analyses. The patterns obtained with the Stroop congruity measure largely corroborated those observed with the Garner measure. In all the experiments in this study, Stroop congruity is defined as the arithmetic difference in RT to congruent (matching) and incongruent (mismatching) color/word pairs in a task, a positive value indicating an advantage in RT to the congruent stimuli. Performance is evaluated in both baseline and filtering tasks. Nonetheless, because only the filtering task contains all the stimuli in the set, our analyses and interpretations will stress filtering Stroop congruity over baseline Stroop congruity (see note 1).

In each experiment, we also analyzed graphically, though not statistically, how overall performance at baseline compares with performance on congruent and incongruent trials in the filtering task. Our baseline measure is unconventional from the perspective of the Stroop tradition, because in this literature the value of the irrelevant dimension is typically not a member of the response set (e.g., the baseline irrelevant color is often black). From the perspective of the Garner tradition, however, our measure is appropriate, because a Garner baseline task is one that involves no irrelevant variation; hence, the irrelevant dimension is held constant at one of its values. In this study, we shall find that these baseline comparisons provide useful insights into the nature of Stroop congruity and its relation to Garner interference.

Average RTs in congruent filtering, incongruent filtering, and baseline trials in each block appear in the top panel (Experiment $1 \mathrm{c}$ ) and bottom panel (Experiment 1w) of Figure 3. The correlation between baseline congruity effects and filtering congruity effects, computed in these and in other experiments of this study according to the averaged Stroop congruity in each block, was -.39 for classifying colors and .10 for classifying words. ${ }^{3}$ In both experiments, an ANOVA revealed a significant interaction between condition (baseline, filtering) and congruity (congruent, incongruent) because the difference in RTs between congruent and incongruent trials was greater in filtering than at baseline [Experiment $1 \mathrm{c}, F(1,31)=4.95$, $M S_{\mathrm{e}}=842.88, p=.03$; Experiment $1 \mathrm{w}, F(1,31)=$ $\left.14.58, M S_{\mathrm{e}}=489.12, p<.001\right]$. Nonetheless, as with Garner interference, Stroop congruity was minuscule even in the filtering tasks: Bonferroni-corrected $t$-test analyses
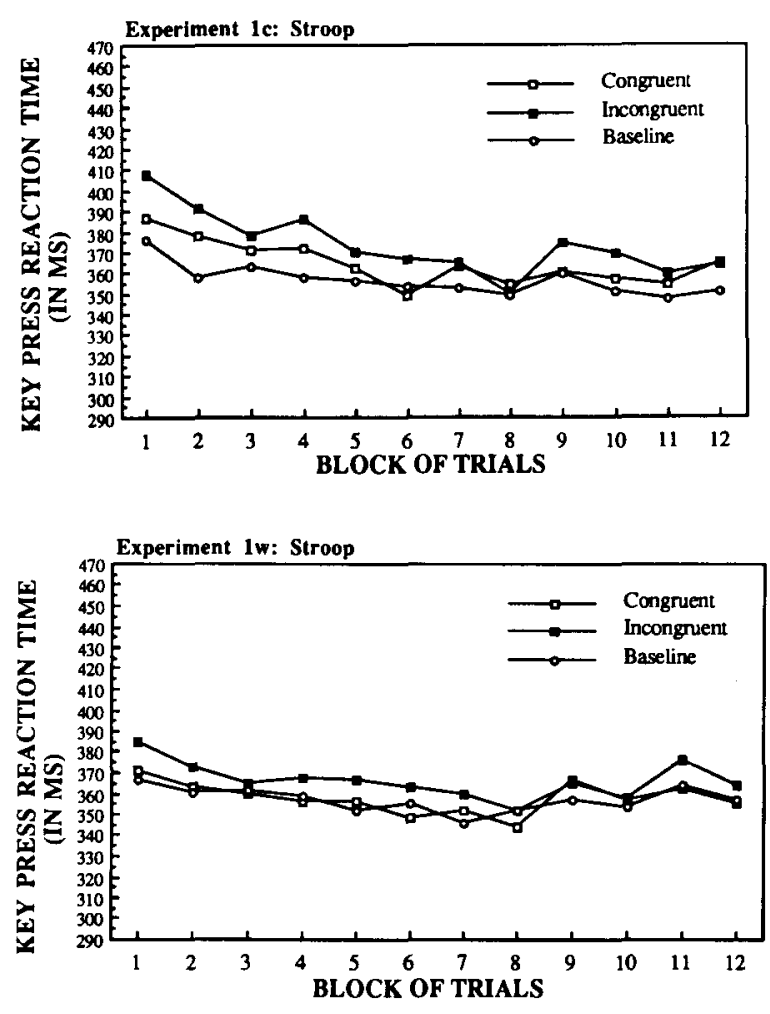

Figure 3. Summary of performance in congruent filtering, incongruent filtering, and average baseline trials in each of 12 blocks of 96 trials with Stroop stimuli (i.e., the color words RED, GREEN, BLUE, or YELLOW printed in either matching or opponent mismatching color). Keypress responses were made either to the colors (top panel; Experiment 1c) or to the color words (bottom panel; Experiment 1w). The two dimensions were matched in baseline discriminability.

showed that baseline congruity did not differ significantly from zero in any block of either experiment, and that filtering congruity was reliable only in Block 6 of Experiment 1c and only in Blocks 6 and 11 of Experiment 1w.

To further investigate Stroop congruity in filtering tasks, a separate ANOVA was performed on RTs in each experiment with block (12 levels) and congruity ( 2 levels) as factors. In Experiment 1c, there was a significant effect of block $\left[F(11,341)=4.40, M S_{\mathrm{e}}=2,404.23, p<\right.$ .001 ], with an asymptote in speed reached by the seventh block. In addition, there was a significant but small effect of Stroop congruity $\left[F(1,31)=10.05, M S_{\mathrm{e}}=\right.$ $1,531.25, p<.01$ ], congruent trials ( $364 \mathrm{msec})$ averaging only $9 \mathrm{msec}$ faster than incongruent trials $(373 \mathrm{msec}$ ). The interaction between block and congruity was not reliable $\left[F(11,341)=1.56, M S_{\mathrm{e}}=606.24\right.$, n.s. $]$. In an ANOVA of error rates, only the effect of congruity was reliable $\left[F(1,31)=7.88, M S_{\mathrm{e}}=.03, p<.01\right]$. Subjects were slightly more accurate in classifying congruent stimuli (.01 errors) than they were in classifying incongruent stimuli (.02 errors).

Planned contrasts $\left(M S_{\mathrm{e}}=1,212.47\right)$ showed that the average size of Stroop congruity in Blocks 1 and $2(11 \mathrm{msec})$ 
was significantly greater than that in Blocks 7 and 8 $(2 \mathrm{msec})[F(1,341)=8.90, p<.01]$, but not significantly different from that in Blocks 9 and $10(13 \mathrm{msec})$ $[F(1,341)=.36, \mathrm{n} . \mathrm{s}]$. Congruity effects disappeared again by Blocks 11 and $12(2 \mathrm{msec})[F(1,341)=5.79$, $p=.02]$. Thus, the small effect of Stroop congruity that did obtain in Experiment Ic was eliminated through practice. As one can see from the top panel of Figure 3, before the congruity effects disappeared, average RTs on baseline trials were slightly faster than RTs on both congruent and incongruent trials. Practice appeared to affect color judgments, then, by causing RTs on both the congruent and the incongruent trials to converge on baseline.

In Experiment 1w, the magnitude of Stroop congruity was also tiny, though greater than the corresponding Garner effects. There was a main effect of block $[F(11,341)=$ $\left.2.40, M S_{\mathrm{e}}=1,592.39, p<.01\right]$ and a main effect of congruity $\left[F(1,31)=32.60, M S_{\mathrm{e}}=457.13, p<.001\right]$, but no interaction between block and congruity $[F(11,341)$ $=1.17, M S_{\mathrm{e}}=346.86, \mathrm{n} . \mathrm{s}$.]. This pattern was replicated in error analysis: An ANOVA revealed a main effect of block $\left[F(11,341)=3.23, M S_{\mathrm{e}}=.01, p<.001\right]$ and a main effect of congruity $\left[F(1,31)=10.29, M S_{\mathrm{e}}=.01\right.$, $p<.01]$, but no interaction $\left[F(11,341)=.42, M S_{\mathrm{e}}=\right.$ .02 , n.s.]. Congruent trials (.011) evoked slightly fewer errors than did incongruent trials (.015).

Average filtering congruity in Blocks 1 and $2(12 \mathrm{msec})$ did not differ from that in Blocks 7 and $8(8 \mathrm{msec})$ $\left[F(1,341)=.85, M S_{\mathrm{e}}=693.72\right.$, n.s. $]$, but did differ from that in Blocks 9 and $10(0 \mathrm{msec})[F(1,341)=6.82$, $p<.01]$. Interestingly, however, a small effect of congruity resurfaced in Blocks 11 and $12(11 \mathrm{msec}),[F(1,341)$ $=.02$, n.s.]. As shown in Figure 3, the congruity effects in the first blocks of trials were characterized by slow responses to incongruent stimuli relative to baseline, but by baseline-level responses to congruent stimuli. This pattern is distinct from that obtained with color judgments. In general, Experiment 1 showed that Stroop congruity was small from the outset and only diminished with practice.

\section{Discussion}

The results of Experiments $1 \mathrm{c}$ and $1 \mathrm{w}$ suggest conclusions similar to those reached by Melara and Marks (1990c): Subjects are able to attend well to one Stroop dimension in the face of irrelevant variation in the other Stroop dimension. In both Experiments $1 \mathrm{c}$ and $1 \mathrm{w}$, the absolute amount of interference-of both the Garner and the Stroop variety - was relatively small. Even in the first block of trials, which invariably contained the largest difference between conditions, the average interference (combining Garner and Stroop effects in filtering) was only $14 \mathrm{msec}$. Thus, even at the outset of testing, the irrelevant dimension of color/word stimuli did not interfere strongly with processing of the relevant dimension.

The small amounts of interference help explain our failure to obtain statistically reliable interactions between condition and block: There was little room for interference effects to diminish. In this regard, though, the present findings differ from those of Melara and Marks (1990c), who did find a significant interaction with color judgments between condition and block; unfortunately, the two studies cannot be compared directly, because only in the present study were baseline discriminabilities evaluated for both the color and the word dimensions. Notwithstanding the absence of statistically significant interactions, planned contrasts revealed that the small intrusive effects that were found virtually disappeared by the end of classification training, for both word and color classification. We may thus conclude that Stroop dimensions are largely separable in information processing, at least when baseline discriminabilities are matched and the response mode is keypress.

A second striking fact about our results is their symmetry: Colors intruded on word classification as much as words intruded on color classification. This finding contrasts with the usual asymmetry found with Stroop stimuli, words typically being more intrusive on color identifications than the reverse. One explanation for our results emphasizes the response modality: Perhaps an asymmetry arises only when a correspondence exists between the stimulus dimension (words) and the response system (explicit naming). This explanation is popular (e.g., McClain, 1983; Pritchatt, 1968; Virzi \& Egeth, 1985), despite the fact that Stroop interference has been obtained with nonspoken responding (e.g., Keele, 1972; Redding \& Gerjets, 1977; Roe, Wilsoncroft, \& Griffiths, 1980). Experiments 3 and 4 of this study evaluate the role of spoken responding in Stroop interactions.

A second explanation for our results, one that we endorse, is that asymmetries, when they are found, emerge from an inequality of baseline discriminabilities (cf. Melara \& Marks, 1990a; Wood, 1975). In Experiment 1 we were quite successful in equating differences in color with differences in word: Baseline discriminabilities were within $1 \mathrm{msec}$ of each other. The results of our tests imply that, under these matched conditions, subjects can achieve symmetric separability between the dimensions of color and word. In the next experiment, we examine the effect on selective attention of mismatches in baseline discriminability.

Despite the negligible congruity effects, the results from Experiment 1 are helpful in distinguishing the effects of attribute identity from the effects of dimensional variation. In baseline tasks, effects of congruity could be caused only by the relative speed or strength in processing individual stimulus attributes, because the irrelevant dimension was held constant throughout the task. Under these conditions, we found no difference in RT between congruent trials (Experiment 1c, $355 \mathrm{msec}$; Experiment 1w, $357 \mathrm{msec}$ ) and incongruent trials (Experiment 1c, 358 msec; Experiment $1 \mathrm{w}, 357 \mathrm{msec}$ ). In contrast, in filtering tasks the two dimensions were varied orthogonally, and this variation caused small effects of congruity to emerge. Thus, dimensional variation, not feature strength, was the factor generating whatever effects of congruity appeared. In the course of this study, we will see that, even when over- 
all congruity effects are substantial, baseline congruity ef fects are invariably minor and correlations between baseline and filtering congruity effects are inconsistent at best. On the basis of these and other results, we will conclude that the relative speed of discriminating values on dimensions, not the speed or strength of processing individual stimulus attributes, is the critical factor underlying Stroop congruity.

It is possible that irrelevant dimensional variation generates Garner interference and Stroop congruity through different mechanisms. This idea helps explain why, relative to baseline, subjects experienced interference from incongruent pairings but no facilitation from congruent pairings, a finding that will reappear throughout this study. The crucial insight is that, if Stroop facilitation were as large as Stroop interference, there would be no Garner interference: The average of congruent and incongruent trials - that is, average performance in filtering-would equal baseline. Thus, the presence of Garner interference suggests an effect of irrelevant dimensional variation over and above that underlying Stroop congruity. Stated another way, the fact that baseline trials entail no irrelevant variation means that comparisons with congruent and incongruent trials enclose a bias toward greater Stroop interference than Stroop facilitation. The frequent absence of facilitation in this study (and in other Stroop research; see MacLeod, 1991) is thus understandable once viewed from the perspective of dimensional interaction and the differential effects of orthogonal variation on selective attention. Later, we will consider more evidence that suggests separate mechanisms for Garner interference and Stroop congruity.

Unlike Melara and Marks's (1990c) experiment, the present experiments included transfer to new stimulus pairs to provide further insight into the effects of practice on selective attention. Generally speaking, subjects transferred well to these new stimuli: After the stimuli were introduced, both the baseline level of responding and the magnitude of interference effects appeared consistent with pretransfer performance, suggesting that semantic satiation plays a relatively unimportant role in Stroop classification. The only exception to this rule was found with the Stroop measure in Experiment 1c. Here, the magnitude of the effect returned to its original level after transfer, although it disappeared again within the remaining blocks of trials. We have no explanation for this exception now; we will be better able to address this issue later, in the context of the remaining experiments.

\section{EXPERIMENTS 2c AND 2w}

In Experiment 2, we examined keypress responding to Stroop dimensions when baseline discriminabilities were mismatched. In particular, we hoped to fabricate a Stroop effect by making one dimension more discriminable than the other. To accomplish this, subjects saw slightly smaller letters and performed at greater screen distances than in Experiment 1, thereby reducing the visual angle of the display. This manipulation caused a slowdown in word classification (Experiment $2 w$ ), but not in color classification (Experiment 2c). If Stroop effects can be attributed, at least in part, to mismatches in baseline discriminability, our manipulation should engender asymmetrical interaction, with the more discriminable dimension (color) affecting the less discriminable dimension (word) more strongly than vice versa. Of course, this predicted pattern is the reverse of the usual Stroop effect. As in Experiment 1 , we examined how the predicted results might be affected by extensive training on the classification task.

\section{Method}

Subjects. Sixty-four subjects participated in this experiment for course credit, 32 in Experiment 2c (23 men, 9 women) and 32 in Experiment 2w (23 men, 9 women). None had participated in Experiment 1.

Stimuli, Apparatus, and Procedure. The apparatus and procedure were identical to those of Experiment 1 . The stimuli were created with the Times 11 font, slightly smaller than that used earlier. In addition, the subjects were seated $255 \mathrm{~cm}$ from the computer screen. The stimuli subtended $.15^{\circ}$ of vertical visual angle and $.36^{\circ}$ of horizontal vertical angle (i.e., $.7 \times 1.6 \mathrm{~cm}$ ), thereby slowing, but not disrupting, the readability of the words. Prior to participation, all subjects were tested for color deficiency and on their ability to read text subtending the visual angles tested. To ensure that word judgments were made on the basis of reading rather than word length, and as a way of equating all color words in horizontal visual angle $\left(.36^{\circ}\right)$, each of the four words was suffixed with the appropriate number of \#s. This modification did not disrupt word readability. The subjects in Experiment $2 c$ classified colors and ignored words; the subjects in Experiment $2 w$ classified words and ignored colors. All other aspects of the experiment duplicated Experiment 1

\section{Results}

Overall performance. Baseline performance in color identification ( $384 \mathrm{msec}$ ) was $116 \mathrm{msec}$ faster than baseline performance in word identification $(500 \mathrm{msec})$, $[t(62)=9.39, p<.001]$. Thus, we were successful in mismatching discriminabilities in favor of color.

The overall error rate was .024 in Experiment 2c, and .026 in Experiment $2 \mathrm{w}$. Speed and accuracy correlated -.55 in Experiment $2 \mathrm{c}$ and .55 in Experiment $2 \mathrm{w}$.

Garner analyses. A summary of performance in baseline and filtering trials at each block is given in Figure 4. In Experiment 2c, an ANOVA of RTs showed a significant effect of block $\left[F(11,341)=2.40, M S_{\mathrm{e}}=1,363.70\right.$, $p<.01]$, no effect of condition $\left[F(1,31)=.27, M S_{\mathrm{e}}=\right.$ 579.91 , n.s. $]$, and no interaction $[F(11,341)=.42$, $M S_{\mathrm{e}}=652.36$, n.s.]. RTs on baseline trials $(384 \mathrm{msec})$ were equivalent to RTs on filtering trials ( $385 \mathrm{msec}$ ), and this pattern remained consistent across blocks of trials. The effect of block was caused by a systematic decrease in RT, from $398 \mathrm{msec}$ in Block 1 to $371 \mathrm{msec}$ in Block 12. This pattern of results was replicated in the error analyses.

A slightly different statistical pattern obtained in Experiment $2 \mathrm{w}$. Here there was no effect of block $[F(11,341)=$ $\left..69, M S_{\mathrm{e}}=1,426.96, p<.01\right]$, a significant effect of condition $\left[F(1,31)=19.21, M S_{\mathrm{e}}=809.43, p<.001\right]$, and no interaction $\left[F(11,341)=.73, M S_{\mathrm{e}}=773.15\right.$, 

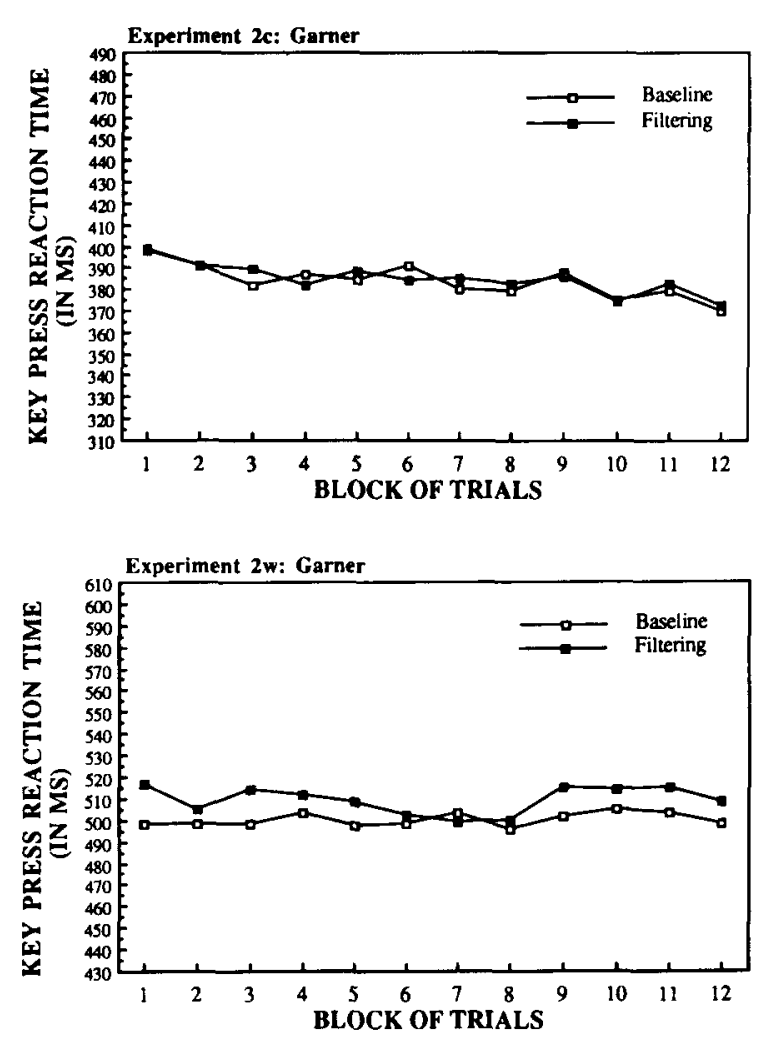

Figure 4. Summary of performance in baseline and filtering trials in each of 12 blocks of 96 trials with Stroop stimuli (i.e., the color words RED, GREEN, BLUE, or YELLOW printed in either matching or opponent mismatching color). Keypress responses were made either to the colors (top panel; Experiment $2 \mathrm{c}$ ) or to the color words (bottom panel; Experiment 2w). The two dimensions were mismatched in baseline discriminability in favor of color judgments.

n.s.]. The effect of condition was minuscule, however: Average filtering RTs $(509 \mathrm{msec})$ were only $9 \mathrm{msec}$ slower than average baseline RTs $(500 \mathrm{msec})$. Moreover, an effect of condition was not found in errors $[F(1,31)=$ $1.17, M S_{\mathrm{e}}=.03, \mathrm{n.s}$.]. No significant differences in RTs were found either in planned comparisons or in Bonferroni $t$-test analyses. In general, then, the pattern of Garner effects in Experiment 2 suggested good selective attention overall, as was found in Experiment 1.

Stroop analyses. Results from Stroop analyses differed from those in Experiment 1, as is shown in Figure 5. The correlation between baseline congruity effects and filtering congruity effects was -.26 in color classification and .07 in word classification. Condition (baseline, filtering) and congruity (congruent, incongruent) interacted in word classification $\left[F(1,31)=28.25, M S_{\mathrm{e}}=1,007.65, p<\right.$ $.001]$, but not in color classification $[F(1,31)=.38$, $M S_{\mathrm{e}}=559.46$, n.s.]. Moreover, no congruity effect differed significantly from zero in any block of color or word baseline trials, or in any color filtering trials. In contrast, when words were classified, Stroop congruity was significantly greater than zero in 9 of 12 blocks of filtering trials.

Further analysis of filtering performance punctuates these findings. In Experiment 2c, an ANOVA of RTs showed a significant effect of block $[F(11,341)=1.83$ $\left.M S_{\mathrm{e}}=1,767.54, p=.05\right]$, no effect of congruity $\left[F(1,31)=3.77, M S_{\mathrm{e}}=487.89\right.$, n.s. $]$, and no interaction $\left[F(11,341)=1.40, M S_{\mathrm{e}}=464.38\right.$, n.s. $]$. RTs on congruent trials $(383 \mathrm{msec}$ ) did not differ on the average from RTs on incongruent trials $(386 \mathrm{msec})$. No significant effects were found in the error analysis.

In contrast, an ANOVA of RTs in Experiment 2w revealed a substantial effect of colors on word judgments, one that was largely unaffected by practice. We found no effect of block $\left[F(11,341)=1.10, M S_{\mathrm{e}}=2,292.34\right.$, n.s. $]$, a large effect of congruity $\left[F(1,31)=62.35, M S_{\mathbf{c}}=\right.$ $1,474.56, p<.001]$, and no interaction $[F(11,341)=$ $1.12, M S_{\mathrm{e}}=553.45$, n.s.]. Subjects responded $22 \mathrm{msec}$ faster to congruent trials ( $498 \mathrm{msec}$ ) than to incongruent trials $(520 \mathrm{msec})$. Error analysis revealed a small effect of block $\left[F(11,341)=1.95, M S_{\mathrm{e}}=.01, p=.03\right]$, a significant effect of congruity $\left[F(1,31)=20.29, M S_{\mathrm{e}}=.01\right.$, $p<.001]$, and no interaction $\left[F(11,341)=1.44, M S_{\mathrm{e}}=\right.$ $.02, \mathrm{n} . \mathrm{s}$.]. Subjects were more accurate on congruent trials (.01) than on incongruent trials (.02). As seen in the bottom panel of Figure 5, RT performance on congruent trials was at baseline level across blocks.
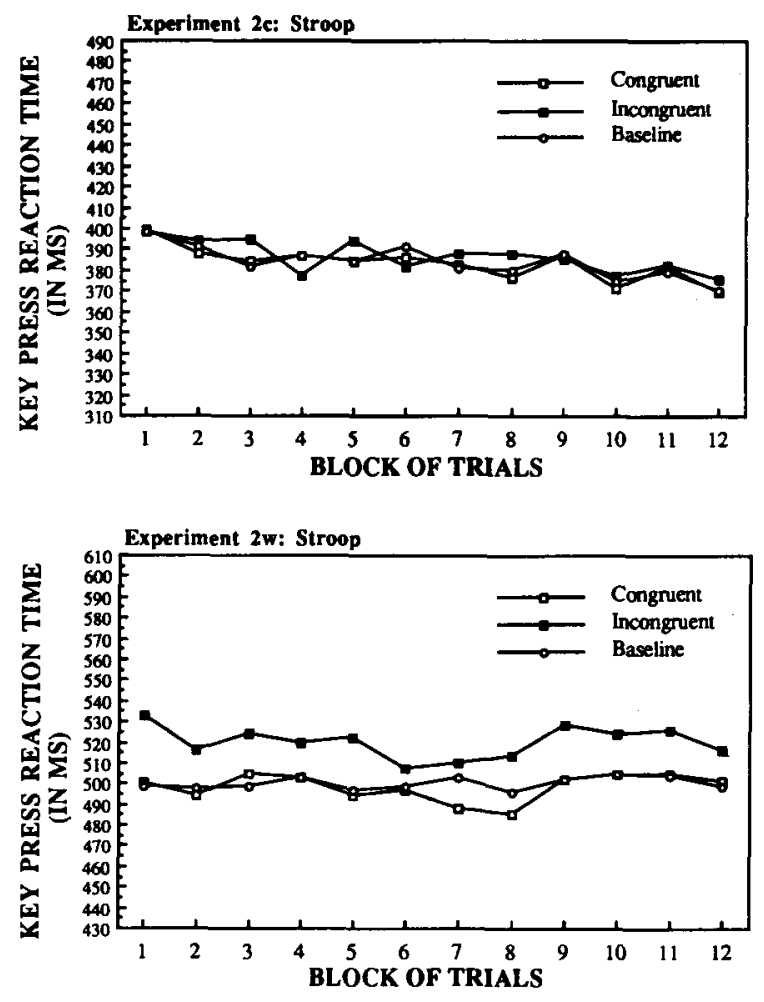

Figure 5. Summary of performance in congruent filtering, incongruent filtering, and average baseline trials in each of 12 blocks of 96 trials with Stroop stimuli (i.e., the color words RED, GREEN, BLUE, or YELLOW printed in either matching or opponent mismatching color). Keypress responses were made either to the colors (top panel; Experiment 2c) or to the color words (bottom panel; Experiment $2 w$ ). The two dimensions were mismatched in baseline discriminability in favor of color judgments. 


\section{Discussion}

The results of Experiment 2 differ in form from those obtained in Experiment 1, at least with the Stroop measure. Keypress performance in response to Stroop stimuli mismatched in discriminability caused an asymmetrical effect of congruity: The less discriminable dimension (word) was affected by the more discriminable dimension (color), but words had no demonstrable effect on color processing. This pattern obtained only in filtering judgments and so, when considered together with the low correlations between baseline congruity and filtering congruity, indicates again the dominant role of relative speed of discrimination in Stroop interaction. The Garner measure showed a slight tendency toward this pattern but, in terms of absolute magnitude of interference, was more consistent with the pattern of separability found in Experiment 1.

When viewed together with Experiment 1, the results clearly suggest dimensional separability between Stroop dimensions. Indeed, our pattern of results is reminiscent of that reported by Garner and Felfoldy (1970) in their analysis of separability between circle size and diameter angle: (1) a symmetry in performance and general lack of interference when baselines are matched (as in our Experiment 1) and, (2) a tendency for asymmetrical interaction when baselines are mismatched (as in our Experiment 2). Our results imply that Stroop dimensions are not special, in the sense that these dimensions do not lead inevitably to a breakdown in selective attention. Indeed, one interpretation of our results is that failures of selective attention in the classifying of Stroop dimensions-indeed, in classifying any pair of separable dimensions-owe to general effects on processing of relative dimensional variation. The remaining experiments of this study explore this conclusion in the context of vocal responding.

An interesting finding from Experiment $2 w$ was that practice at classifying the less discriminable dimension did little to ameliorate the disruptive effects of the more discriminable dimension. This finding may be related to the finding that subjects' speed of discrimination did not improve across blocks. In particular, the fact that subjects did not increase their speed in classifying words throughout the experimental session may have caused the mismatch in discriminability between dimensions to remain substantial. This, in turn, may have helped to maintain the interfering influences of the color dimension. At this point, it is unclear whether (and how much) additional practice at word discrimination would have contributed to a diminution in interference. At the least, though, the results suggest that the intrusive effects of mismatched discriminabilities are resistant to improvement.

\section{EXPERIMENTS 3c AND 3w}

The results from Experiment 1 suggested dimensional separability between Stroop dimensions when baseline discriminabilities were matched. The results from Experiment 2 revealed that asymmetrical effects of congruity could be instigated by asymmetries in baseline discriminability. The subjects in both experiments made their clas- sification judgments by pressing keys. The effect discovered by Stroop, however, occurred with spoken responses. The following question can therefore be posed: Does selective attention succeed when subjects respond to Stroop dimensions orally? We addressed this question in Experiments 3 and 4. In Experiment 3, we presented subjects with the stimulus differences found in Experiment 1 to be matched in baseline discriminability. But the results differed from those obtained in Experiment 1, and the differences are telling about how best to define the concept of baseline discriminability.

\section{Method}

Subjects. Thirty-two subjects participated, 16 in Experiment 3c ( 5 men, 11 women) and 16 in Experiment 3w ( 7 men, 9 women). None had participated in either of the earlier experiments.

Stimuli, Apparatus, and Procedure. The stimulus set and apparatus were identical to those in Experiment 1. The subjects in Experiment $3 \mathrm{c}$ named colors, ignoring words; the subjects in Experiment $3 \mathrm{w}$ read words, ignoring colors. Responses were made by speaking into a Realistic 33-1063 clip microphone, which triggered a locally designed voice-activated relay. Latencies were measured in milliseconds by a hardware timer, as in previous experiments. The procedure was otherwise identical to that in Experiment 1, except that an experimenter remained in the testing room throughout the session. The experimenter recorded all trials in which the subject committed a misidentification. An error was defined as any misspoken response, even if the response contained the correct answer (e.g., "gred" for "red"). The experiment lasted approximately $1 \mathrm{~h}$.

\section{Results}

Overall performance. Baseline color identification $(504 \mathrm{msec})$ was $80 \mathrm{msec}$ slower than baseline word identification $(424 \mathrm{msec})[t(30)=5.39, p<.001]$. This result indicates that baseline discriminabilities were mismatched, despite the fact that stimulus values were identical to those used in Experiment 1.

The overall error rate was .03 in Experiment 3c, and .02 in Experiment 3w. Speed and accuracy correlated .39 in Experiment $3 c$ and -.41 in Experiment $3 w$.

Garner analyses. The performance in baseline and filtering conditions in each of 12 blocks of trials appears in Figure 6. An ANOVA of RTs in Experiment 3c revealed a significant effect of block $[F(11,165)=4.57$, $\left.M S_{\mathrm{e}}=3,273.82, p<.001\right]$, and a significant effect of condition $\left[F(1,15)=33.33, M S_{\mathrm{e}}=4,278.25, p<.001\right]$, but no interaction $\left[F(11,165)=.97, M S_{\mathrm{e}}=1,120.46\right.$, n.s.]. The subjects responded $39 \mathrm{msec}$ faster on baseline trials $(504 \mathrm{msec})$ than they did on filtering trials $(543 \mathrm{msec})$. This effect also obtained in the error analysis $\left[F(1,15)=14.16, M S_{\mathrm{e}}=.04, p<.01\right]$.

The pattern of results differed in Experiment $3 w$. Here the ANOVA of RTs showed no effect of block $[F(11,165)$ $=.84, M S_{\mathrm{e}}=1,000.25$, n.s.], no effect of condition $\left[F(1,15)=.00, M S_{\mathrm{e}}=648.79\right.$, n.s. $]$, and no interaction $\left[F(11,165)=.87, M S_{\mathrm{e}}=443.05\right.$, n.s. $]$. In the error analysis, only the effect of block was reliable $[F(11,165)=$ $\left.1.96, M S_{\mathrm{e}}=.02, p=.04\right]$. Bonferroni analyses revealed that Garner interference did not differ from zero in any block of trials (see Figure 6). 

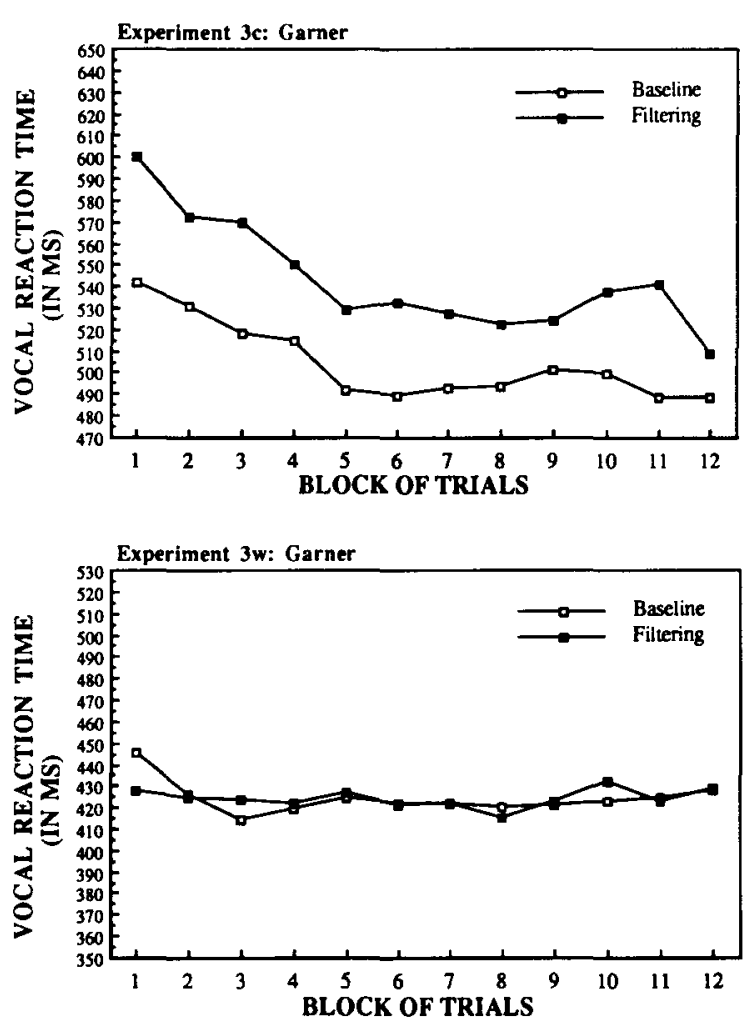

Figure 6. Summary of performance in baseline and filtering trials in each of 12 blocks of 96 trials with Stroop stimuli (i.e., the color words RED, GREEN, BLUE, or YELLow printed in either matching or opponent mismatching color). Vocal responses were made either to the colors (top panel; Experiment 3c) or to the color words (bottom panel; Experiment $3 \mathrm{w}$ ). The two dimensions were mismatched in baseline discriminability in favor of word judgments.

Stroop analyses. The pattern obtained with Stroop effects was similar to that obtained with Garner effects, as can be seen in Figure 7. As in previous experiments, the effects of congruity were more apparent in filtering tasks than in baseline tasks, leading, in both experiments, to a significant interaction between condition and congruity [Experiment 3c, $F(1,15)=31.79, M S_{\mathrm{e}}=3,297.26$, $p<.001$; Experiment 3w, $F(1,15)=10.41, M S_{\mathrm{e}}=$ $362.41, p<.01]$. The correlation between baseline and filtering congruity effects was .30 in Experiment $3 c$ and .11 in Experiment 3w. The asymmetry in Stroop performance is strongly revealed by how frequently congruity effects exceeded zero in color rather than word classification: In the classifying of colors, congruity effects were reliable in 5 of 12 baseline blocks and 12 of 12 filtering blocks; in the classifying of words, however, the effects were not reliable in any baseline blocks and in only 1 of 12 filtering blocks.

In further tests of filtering congruity, an ANOVA of RTs in Experiment 3c showed a main effect of block $\left[F(11,165)=4.40, M S_{\mathrm{e}}=4,942.38, p<.001\right]$, a main effect of congruity $\left[F(1,15)=67.34, M S_{\mathrm{e}}=6,655.34\right.$, $p<.001]$, and a significant interaction $[F(11,165)=$ $\left.2.24, M S_{\mathrm{e}}=907.82, p=.01\right]$. On the average, the sub- jects responded $69 \mathrm{msec}$ faster on congruent trials $(509 \mathrm{msec})$ than on incongruent trials $(578 \mathrm{msec})$. The subjects were also more accurate on congruent trials (.01 errors) than on incongruent trials (.03 errors) $[F(1,15)=$ 29.05, $\left.M S_{\mathrm{e}}=.04, p<.001\right]$.

The nature of the RT interaction can be understood through the series of planned contrasts $\left(M S_{e}=1,815.64\right)$. The first pair of blocks yielded an enormous congruity effect $(86 \mathrm{msec})$. The effect dropped to $53 \mathrm{msec}$ by Blocks 7 and $8[F(1,165)=9.65, p<.01]$. However, the congruity effect resurged following transfer to the alternate stimulus set $[F(1,165)=1.66$, n.s. $]$. Then, by the last two blocks of trials, the subjects were able to reduce the congruity effect to $58 \mathrm{msec}[F(1,165)=6.88, p<.01]$. It is important to emphasize that the congruity effect was significantly greater than zero in each block of trials.

The ANOVA of RTs in the filtering tasks of Experiment $3 w$ showed an average difference between congruent and incongruent trials of $8 \mathrm{msec}$, which did reach statistical significance $\left[F(1,15)=11.28, M S_{\mathrm{e}}=520.07, p<\right.$ $.01]$. This effect was also found with errors $[F(1,15)=$ 4.77, $\left.M S_{\mathrm{e}}=.01, p=.05\right]$. There was no RT effect of block $\left[F(11,165)=.49, M S_{\mathrm{e}}=1,285.73\right.$, n.s. $]$ and no
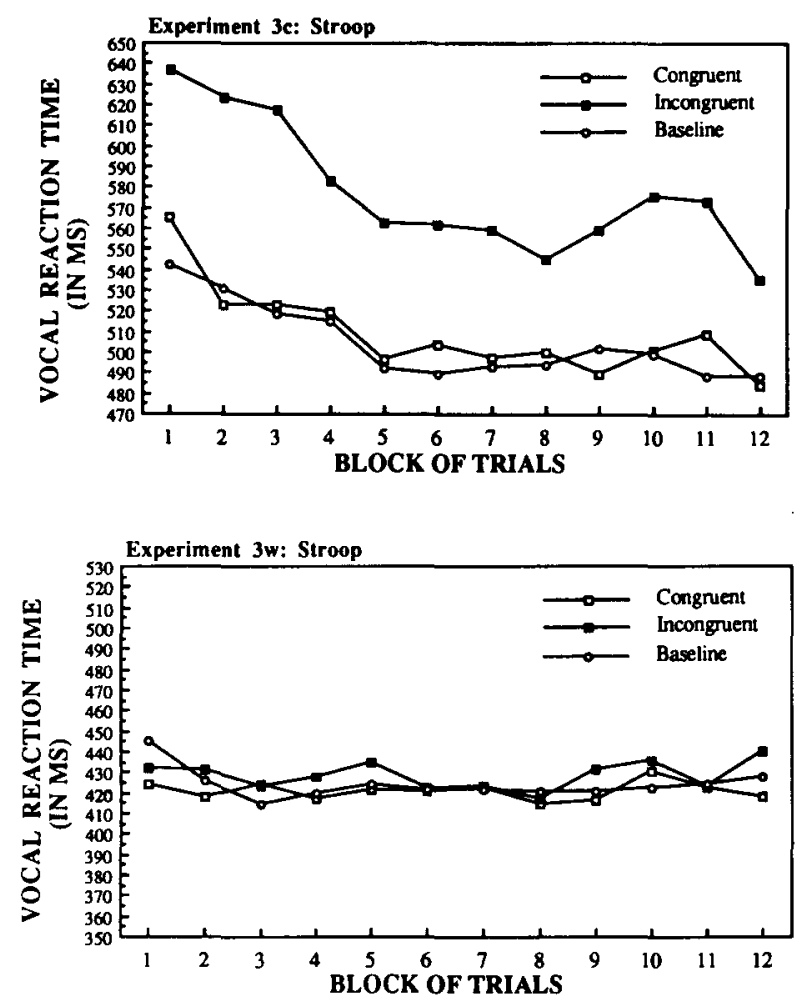

Figure 7. Summary of performance in congruent filtering, incongruent filtering, and average baseline trials in each of 12 blocks of 96 trials with Stroop stimuli (i.e., the color words RED, GREEN, BLUE, or YELLOW printed in either matching or opponent mismatching color). Vocal responses were made either to the colors (top panel; Experiment 3c) or to the color words (bottom panel; Experiment $3 w$ ). The two dimensions were mismatched in baseline discriminability in favor of word judgments. 
interaction between condition and block $[F(11,165)=$ $1.44, M S_{\mathrm{e}}=280.10$, n.s.].

\section{Discussion}

The typical Stroop asymmetry obtained in Experiment 3: Words strongly affected color judgments, but colors had, at most, a scant effect on word judgments. The effect of irrelevant words on color identification was substantial from the outset (e.g., $86 \mathrm{msec}$ of congruity in the first two blocks of trials), and it remained significantly greater than zero despite continued exposure to the task. These results occurred, however, in the context of a substantial mismatch in baseline discriminability: Words were much easier to discriminate than colors. The result is therefore similar conceptually (but opposite in detail) to that found in Experiment 2: The more discriminable dimension intruded on the less discriminable dimension more strongly than vice versa. Unlike in previous experiments, the pattern was even evident in baseline Stroop congruity, although, as before, these effects were minor in comparison with those obtained in filtering.

It is interesting that the stimulus values that led to equal baseline discrimination when the response mode consisted of keypressing (Experiment 1) led to unequal discrimination in the present experiment. This implies that the construct of dimensional variation should be defined globally, across the cognitive system, and not restricted to the level of perceptual analysis. One possible definition of baseline discriminability, therefore, is that it is the time necessary to attend to, perceive, identify, and respond to values varying on a single dimension. Response mode is obviously an intricate part of this definition; the present results demonstrate that changes in response mode-from manual to vocal-powerfully affect speeds of discriminating baseline values. The issue remains, however, whether the traditional Stroop effect in spoken responding still obtains when global baseline discriminabilities are matched. We address this issue in Experiment 4.

Other results from Experiment 3 are helpful for obtaining a full picture of selective attention to Stroop dimensions. As in previous experiments, we found close, but not exact, ties between magnitudes of Garner interference and Stroop congruity. In color identification, Stroop congruity was stronger than Garner interference, but it was also slightly more variable; in word judgments, both effects were extremely small. The general pattern might suggest that Garner interference and Stroop congruity are largely interchangeable measures of failure to attend selectively (but see Experiment 4). Nonetheless, differences between the two measures were apparent. First, like the subjects in Experiment 2w, the subjects in Experiment 3c responded to the congruent stimuli (in filtering) at baseline level (see Figure 7); as discussed earlier, the fact that Stroop interference exceeds Stroop facilitation indicates that effects of Stroop congruity occur on top of the RT slowdown observed in filtering (i.e., Garner interference). Second, Stroop congruity appeared somewhat more sensitive to effects of intrusion, as they were evident even after Garner effects had disappeared. Finally, effects of congruity were more strongly affected by transfer to new stimulus sets (cf. Reisberg et al., 1980), a finding analogous to that obtained in Experiment 1. Later we will discuss possible reasons why differences emerged between these two measures.

\section{EXPERIMENTS 4c AND 4w}

We consider the baseline speed of discrimination to depend on which stimulus values are selected, and not to be intrinsic to the nature of the dimensions themselves. Accordingly, it should be possible to make color variation more or less discriminable than words, whatever the response mode. The results of Experiment 3 suggest that baseline discriminability needs to be defined in terms of both stimuli and responses, because different response modes will yield different baseline speeds. In Experiment 4, we adopted the tack used in Experiment 2: We enhanced baseline color speed relative to baseline word speed by shrinking the visual angle of the Stroop stimuli. This allowed us to ask how selective attention fares when subjects make vocal responses to Stroop dimensions, but when, unlike in Stroop's original study, colors and words are equated in discriminability.

\section{Method}

Subjects. Thirty-two Purdue undergraduate students participated in partial fulfillment of a course requirement. Half the subjects (8 men, 8 women) participated in Experiment $4 c$, and half $(5$ men, 11 women) in Experiment $4 \mathrm{w}$. None had served in any of the earlier experiments.

Stimuli, Apparatus, and Procedure. The stimuli were identical to those in Experiment 2. The subjects sat at a uniform distance of $135 \mathrm{~cm}$ from the CRT screen. Pilot work indicated that, at this distance, baseline vocal responses to words were approximately equal to baseline vocal responses to colors. The apparatus and procedure were identical to those in Experiment 3. Each experiment lasted approximately $1 \mathrm{~h}$.

\section{Results}

Overall performance. Baseline word discrimination (509 msec) was $9 \mathrm{msec}$ slower than baseline color discrimination ( $500 \mathrm{msec})$; this difference was not reliable $[t(30)=.45$, n.s. $]$. Thus, as in Experiment 1, we have succeeded in matching color and word in baseline discriminability.

The overall error rate was .03 in Experiment $4 \mathrm{c}$ and .01 in Experiment $4 w$. Speed and accuracy correlated .36 in Experiment $4 c$ and -.10 in Experiment $4 w$.

Garner analyses. Performance in baseline and filtering trials is summarized in the panels of Figure 8. In Experiment 4c, an ANOVA of RTs uncovered a significant effect of block $\left[F(11,165)=2.31, M S_{\mathrm{e}}=3,372.00, p=\right.$ $.01]$ and no effect of condition $\left[F(1,15)=3.92, M S_{\mathrm{e}}=\right.$ $1,018.55$, n.s.], but there was a significant interaction $\left[F(11,165)=2.61, M S_{\mathrm{e}}=905.99, p<.01\right]$. As can be seen in Figure 8, Garner interference in color classification was $54 \mathrm{msec}$ on the first block of trials, but averaged only $2 \mathrm{msec}$ on the remaining blocks of trials. 

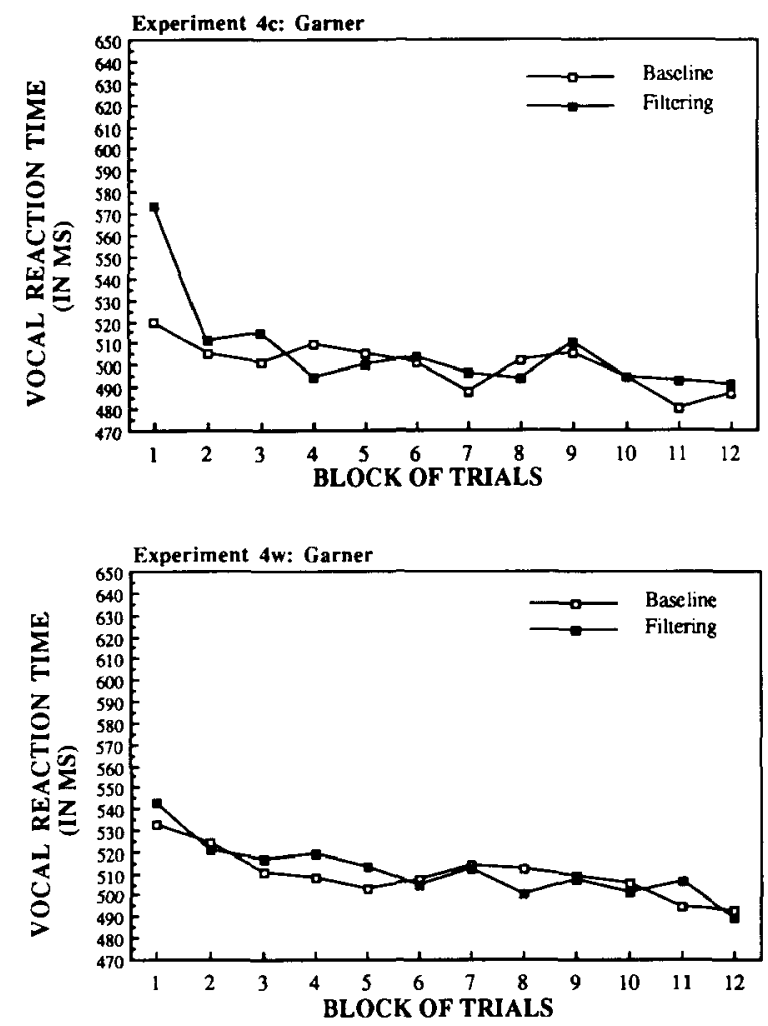

Figure 8. Summary of performance in baseline and filtering trials in each of 12 blocks of 96 trials with Stroop stimuli (i.e., the color words RED, GREEN, BLUE, or YELLOW printed in either matching or opponent mismatching color). Vocal responses were made either to the colors (top panel; Experiment 4 c) or to the color words (bottom panel; Experiment $4 \mathrm{w}$ ). The two dimensions were matched in baseline discriminability.

Error analysis revealed a difference between baseline (.02) and filtering $(.03)\left[F(1,15)=9.33, M S_{\mathrm{e}}=.03, p<\right.$ .011 , but no other effects. Planned contrasts of RTs $\left(M S_{\mathrm{e}}=1,811.98\right)$ showed that interference in the first two blocks of trials $(30 \mathrm{msec})$ was significantly greater than interference in Blocks 7 and $8(0 \mathrm{msec})[F(1,165)=$ $7.84, p<.01]$, Blocks 9 and $10(2 \mathrm{msec})[F(1,165)=$ $6.65, p=.01]$, and Blocks 11 and $12(9 \mathrm{msec})[F(1,165)$ $=3.97, p<.05]$. The principal finding is that, unlike in Experiment 3, relatively little Garner interference obtained in spoken color judgments.

Word identification also showed no Garner interference $\left[F(1,15)=.82, M S_{\mathrm{e}}=396.50\right.$, n.s. $]$. There was an effect of block $\left[F(11,165)=2.77, M S_{\mathrm{e}}=1,577.15\right.$, n.s.], but no interaction between condition and block $[F(11,165)$ $=1.24, M S_{\mathrm{e}}=387.79$, n.s.]. There were no significant effects of errors. In general, Garner analyses in Experiment 4 suggest excellent selective attention to either colors or words.

Stroop analyses. The effects of Stroop congruity resemble the Garner effects, as can be seen in Figure 9. In both experiments, filtering congruity was larger than baseline congruity, as is evidenced by an interaction between condition and congruity [Experiment $4 \mathrm{c}, F(1,15)=$
$10.19, M S_{\mathrm{e}}=570.56, p<.01 ;$ Experiment $4 \mathrm{w}, F(1,15)=$ $\left.10.37, M S_{\mathrm{e}}=386.60, p<.01\right]$. The correlation between baseline congruity and filtering congruity was -.07 in Experiment $4 c$ and .34 in Experiment $4 w$. Congruity effects were inappreciable in both experiments. No baseline congruity effects differed significantly from zero. In the filtering tasks, only 1 of 12 blocks in Experiment $4 \mathrm{c}$ and 2 of 12 blocks in Experiment $4 \mathrm{w}$ showed reliable effects.

Stroop congruity in filtering was analyzed separately by experiment. For color RT judgments, there was a main effect of block $\left[F(11,165)=3.41, M S_{e}=4,815.10, p<\right.$ $.001]$, a main effect of congruity $[F(1,15)=26.95$, $\left.M S_{\mathrm{e}}=1,506.19, p<.001\right]$, and a significant interaction $\left[F(11,165)=4.16, M S_{\mathrm{e}}=717.68, p<.001\right]$. The congruity effect was $21 \mathrm{msec}$ on the average in Experiment $4 \mathrm{c}$. The subjects were also more accurate on congruent trials (.02 errors) than on incongruent trials (.04 errors) $\left[F(1,15)=16.55, M S_{\mathrm{e}}=.03, p<.01\right]$.

Figure 9 shows that the RT interaction between congruity and block was due to a drop in Stroop congruity as the blocks of trials progressed. Congruity in Blocks 1 and 2 averaged $47 \mathrm{msec}$, significantly more $\left(M S_{\mathrm{e}}=\right.$ $1,435.36)$ than congruity in Blocks 7 and $8(13 \mathrm{msec})$ $[F(1,165)=17.05, p<.001]$, Blocks 9 and 10 $(13 \mathrm{msec})[F(1,165)=12.85, p<.001]$, or Blocks 11 and $12(25 \mathrm{msec})[F(1,165)=5.64, p=.02]$.
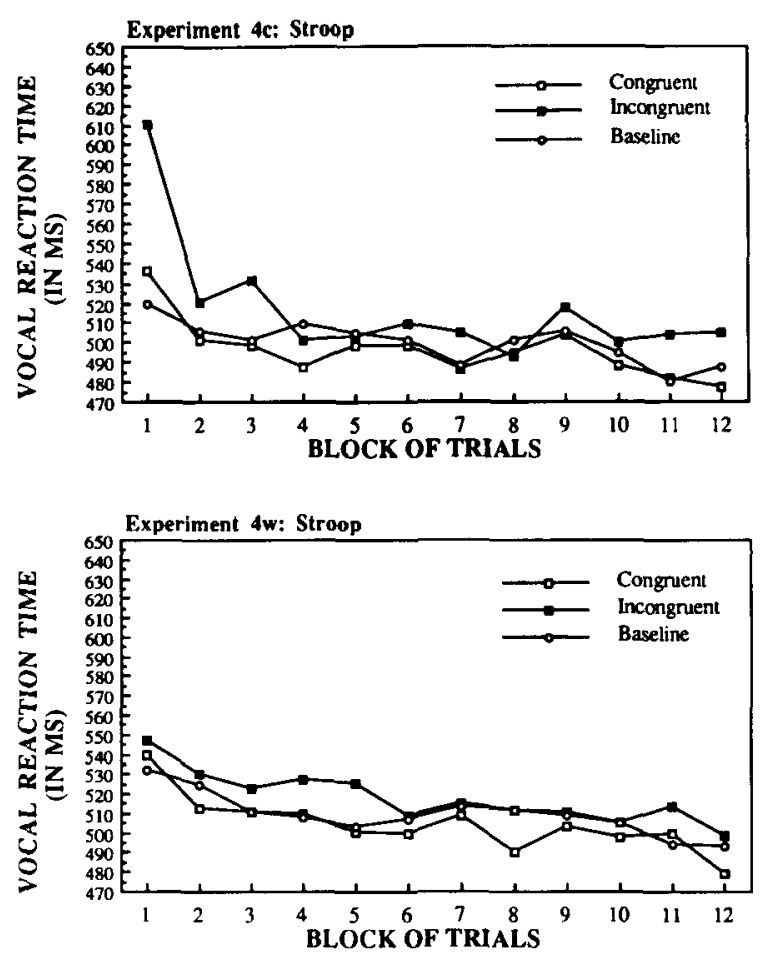

Figure 9. Summary of performance in congruent filtering, incongruent filtering, and average baseline trials in each of 12 blocks of 96 trials with Stroop stimuli (i.e., the color words RED, GREEN, BLUE, or yELLOW printed in either matching or opponent mismatching color). Vocal responses were made either to the colors (top panel; Experiment 4c) or to the color words (bottom panel; Experiment 4w). The two dimensions were matched in baseline discriminability. 
In Experiment $4 w$, there was a significant effect of block $[F(11,165)=2.64, p<.01]$ and a significant effect of congruity $\left[F(1,15)=34.67, M S_{\mathrm{e}}=523.58, p<\right.$ $.001]$, but no interaction. The congruity effect averaged only $14 \mathrm{msec}$ across blocks (see Figure 9). No effects were obtained in error analyses.

\section{Discussion}

When considered along with the earlier experiments, Experiment 4 demonstrates that baseline discriminability is critical to Stroop interactions. Baseline color judgments in this experiment were roughly equal to baseline word judgments. This caused a pattern of results significantly different from that observed in Experiment 3. There, the usual Stroop asymmetry was observed; here, subjects displayed meager, fleeting, and generally symmetrical effects of irrelevant variation. We observed no Garner interference in either dimension after classification practice. In both dimensions, we observed relatively small and volatile effects of filtering congruity. We found no effects of baseline congruity, which, in the context of filtering congruity, demonstrates again what little influence relative speed of processing individual stimulus attributes has on selective attention. In sum, the results of Experiment 4 underscore our view that the degree of irrelevant variation, not the nature of stimuli or responses, is the dominant factor underlying Stroop congruity effects.

This conclusion is at odds with the model proposed by Virzi and Egeth (1985), who contend that the Stroop asymmetry represents the need to translate colors into an oral response code, which is the natural code of color words. Their model would predict that Experiment 4 should replicate Experiment 3 because, in both experiments, naming responses required translation, and so should have suffered interference from irrelevant words. Yet, in Experiment 4, we found that trial-to-trial changes in word caused little disruption in naming performance, which differs strikingly from the results of Experiment 3.

Response mode is, admittedly, a factor of some importance; after all, the change from keypress to vocal responding was the reason that baseline levels matched in Experiment 1 but not in Experiment 3. Nevertheless, the fact that the results from Experiment 4 so closely resembled the results from Experiment 1, yet differed markedly from the results of Experiment 3, demonstrates that the role of translation processes is, at best, secondary to the role of discriminability. In previous studies, the factors that may cause the Stroop effect have been discussed and tested. The present study is unique in pitting some of the hypothesized factors against one another. Our conclusion that baseline discriminability is paramount among factors can thus be made with greater confidence than has hitherto been possible.

Experiment 4 was also important in again revealing differences between Stroop congruity and Garner interference. For both color and word judgments, Garner effects were virtually absent throughout the session, suggesting dimensional separability. But Stroop congruity was numerically, if not statistically, greater than zero in both Experiments $4 c$ and $4 w$. These results indicate that the Stroop and Garner measures are not fully interchangeable, even though both reflect the effects of dimensional variation on selective attention and, as we have seen, both are strongly under the control of relative baseline discriminability. The imperfect correspondence we observed between the two measures appears to conflict with Pomerantz's (1983, 1986) account, which predicts that Stroop congruity will not be found without Garner interference. Of course, one possible explanation is that Garner effects are simply less sensitive for gauging subjects' ability to attend selectively, thereby accounting for the differences in magnitude.

But evidence amassed throughout this study supports a second explanation: namely, that dimensional interactions have multiple causes, some of which are captured best by the Garner measure, some captured best by the Stroop measure (i.e., with corresponding dimensions), but most captured well by both measures. The operation of multiple mechanisms explains the lack of perfect consistency between the two indices, with effects measured by Stroop congruity remaining after Garner effects had disappeared. It also explains why Stroop interference usually exceeds Stroop facilitation. And, the account fits our observation that the Garner and Stroop indices were affected differentially by transfer to new stimuli.

The idea that cognitive systems handle dimensional variation through multiple mechanisms is supported further by evidence that when certain dimensions are paired, the Garner measure is more robust than the Stroop measure. Melara and Marks (1990b) showed, for example, that the auditory dimensions of pitch and loudness lead to strong Garner effects in the face of ephemeral congruity effects, suggesting a separate mechanism particular to the Garner effects. Unfortunately, the present study is ill equipped to identify these putative mechanisms, or to distinguish this explanation from the earlier, or other possible, explanations. We note only that the different courses of Garner interference and Stroop congruity, as observed in this study, testify to the importance of comparing these measures under different conditions.

\section{GENERAL DISCUSSION}

Four experiments were conducted to investigate possible causes of the Stroop asymmetry. The experiments were formulated from the perspective of research and theory on dimensional interaction. From this perspective, it was hypothesized that the Stroop asymmetry might derive in part from a processing mismatch in baseline discriminability between stimulus dimensions, with typical values on the color dimension being more difficult to discriminate, and hence more easily affected during classification, than typical values on the color-word dimension. The hypothesis was tested in a modification of Garner's 
speeded classification paradigm, where both Stroop congruity and Garner interference were measured in each of 12 blocks of trials.

In Experiment 1, keypress responses were made to colors and words matched in discriminability; in this case, we found symmetrical classification performance, and minor effects of Stroop congruity and Garner interference. The small effects that did occur were reduced considerably through classification practice. In Experiment 2, keypress responses were intentionally mismatched in discriminability, with colors made more discriminable than color words. Under these conditions, a reverse Stroop effect was obtained: Word classifications were affected by variation in colors, but color classifications were largely unaffected by variation in words. Practice did little to overcome these intrusive effects. In Experiment 3, the usual Stroop asymmetry was obtained in vocal responses to colors and color words; this pattern was accompanied by (1) a corresponding asymmetry in Garner interference (i.e., disruption mainly in color judgments) and, importantly, (2) a mismatch in discriminability in favor of word judgments, despite the fact that the stimulus values were identical to those tested in Experiment 1. The intrusive effects of the more discriminable dimension were not alleviated with practice. In Experiment 4, vocal responses were intentionally matched in discriminability. This eliminated the Stroop effect found in Experiment 3; we now observed tiny and symmetrical effects of congruity across classification judgments.

In the present study, we have uncovered new and valuable information about the classic Stroop phenomenon. In a single series of experiments, we explored the individual and interactive influences of three critical variables-baseline discriminability, response mode, and practice-on two different measures of dimensional interaction-Stroop congruity and Garner interference. To the best of our knowledge, an analysis of this scope has never appeared before. Our results indicate that although each variable affected each measure to some degree, baseline discriminability dominated as the major factor controlling interactive relations. In particular, we found that it was discriminability per se (i.e., the degree of difference and trial-to-trial change along a dimension), rather than the speed or strength of processing particular stimulus features, that underlies Stroop interaction. The role of relative discriminability has been largely ignored in discussions of the Stroop effect (see MacLeod, 1991). Its fundamental importance, as demonstrated in this study, allows us to recast the Stroop phenomenon as a problem of dimensional separability. In the remainder of this article, we discuss implications for issues in selective attention and dimensional interaction.

\section{Mandatory and Optional Processes in Selective Attention}

Melara, Marks, and Lesko (1992) recently reintroduced and extended the distinction made earlier by Garner (1974a) between mandatory and optional processes (see also Melara, 1990; Pomerantz, 1991). Mandatory processes are obligatory, occur under all circumstances, and reflect intrinsic constraints on the cognitive system. Optional processes, on the other hand, are determined by circumstance and are subject to modification or manipulation by context, learning, or strategy.

In the present context, mandatory processes are those that cause selective attention always to fail. This is because, in filtering tasks, subjects can perform optimally, in the sense of maximizing their speed and accuracy (see Green \& Swets, 1966), only if they always ignore variation on the irrelevant dimension (see Ashby \& Maddox, 1992; Melara, Marks, \& Potts, in press-a). Consistent failure to be optimal suggests the presence of mandatory disruptions in selective attention. On the other hand, inconsistent success in performing optimally suggests the presence of optional processes.

In this study, we found that Stroop dimensions appear nearly separable under certain conditions (e.g., following practice when dimensions are matched in discriminability), but that they interact asymmetrically under other conditions (e.g., when discriminabilities are mismatched). The fact that selective attention can sometimes succeed implies that any crosstalk that does occur, between whatever psychological mechanisms act on color and/or color word information, is not fundamental to the cognitive system. In other words, interaction is not inevitable in the classifying of Stroop dimensions: The magnitude, the presence or absence, and even the form (regular or reverse) of the Stroop effect is easily manipulated (e.g., Flowers et al., 1979), especially by the degree of match in baseline discriminability. In this sense, it appears that the Stroop effect is an optional effect.

But this conclusion is intrinsically weak, because, by our definitions, it is conceivable that all cognitive effects are optional; that is, any given psychological effect may disappear under the appropriate experimental circumstances. In our view, a more productive approach is to identify the nature of the processes that cause cognitive effects to emerge. We believe that such processes can be meaningfully classified as either mandatory or optional. Specifically, regardless of whether the Stroop effect is optional (i.e., in the sense that it does not always occur), when it does occur, the precipitating processes may be mandatory. Thus, we claim that identifying the mandatory processes of attention involves first identifying the conditions under which selective attention always fails.

Logically speaking, it is easier to identify an optional process than it is to identify a mandatory one. This is because one can only induce mandatory processes from an absence of exceptions. Although a particular effect may be evident under all the circumstances tested to date, there is no guarantee that the effect will withstand all forthcoming strategies and manipulations. Thus, our goal of isolating the conditions under which selective attention always fails is fraught with logical limitations. Still, good evidence does exist for several mandatory processes of attention. For example, the pairing of so-called integral dimensions, 
like the color dimensions of saturation and brightness, may lead inevitably to failures of selective attention in information-processing tasks. Melara, Marks, and Potts (in press-b) found that subjects always suffered Garner interference when classifying color stimuli, despite close matches in baseline discriminability and over 1,400 trials of classification practice. Results like theirs suggest that characteristics intrinsic to color dimensions (or other integral dimensions) cause a mandatory disruption of attention (cf. Callaghan, 1984). Results reported by Yantis and Jonides (1984; Jonides \& Yantis, 1988) indicate that the abrupt onset of a visual stimulus can obligatorily capture attention, suggesting perhaps another mandatory process in attention.

Results reported here imply that irrelevant dimensional variation is processed obligatorily when it is larger than relevant variation. Mandatory processing is indicated by the fact that the more discriminable dimension always caused a failure of selective attention to the less discriminable dimension. Mandatory processing is also signaled by the inability of practice to ameliorate these intrusive effects. Interestingly, practice typically helped selective attention to the more discriminable dimension. The fact that practice acts nonuniformly implies that disruptive effects on selective attention are (1) optional on the more discriminable dimension, but (2) mandatory on the less discriminable one. Of course, practice was, by definition, limited to a finite window (i.e., 12 blocks of trials); effects of more extended practice are still unknown. At the least, though, we may conclude that practice effects are lawful, and that they can serve as converging evidence for conclusions about mandatory processing.

A final thought: It is worth noting that our conclusions about mandatory and optional processes, together with our hypothesis, tested in the present study, that mismatches in discriminability underlie the traditional Stroop effect, emerged from a reconsideration of Stroop's original ideas. Indeed, what is remarkable to us about the present research is that, despite almost 60 years and over 700 studies since Stroop published his article, fundamental new insights can still be derived from his discovery.

\section{REFERENCES}

Ashby, F. G., \& Maddox, W. T. (1992). A response time theory of separability and integrality in speeded classification. Manuscript submitted for publication.

Ashby, F. G., \& Townsend, J. T. (1986). Varieties of perceptual independence. Psychological Review, 93, 154-179.

Callaghan, T. C. (1984). Dimensional interaction of hue and brightness in preattentive field segregation. Perception \& Psychophysics, 36, 25-34

Clark, H. H., \& Brownell, H. H. (1976). Position, direction, and their perceptual integrality. Perception \& Psychophysics, 19, 328-334.

Cohen, J. D., Dunbar, K., \& McClelland, J. L. (1990). On the control of automatic processes: A parallel distributed processing account of the Stroop effect. Psychological Review, 97, 332-361.

Dunbar, K., \& MACLEOD, C. M. (1984). A horse race of a different color: Stroop interference patterns with transformed words. Journal of Experimental Psychology: Human Perception \& Performance, 10, 622-639.
Dyer, F. N. (1973). The Stroop phenomenon and its use in the study of perceptual, cognitive, and response processes. Memory \& Cognition, 1, 106-120.

Dyer, F. N., \& Severance, L. J. (1972). Effects of irrelevant colors on reading of color names: A controlled replication of the "reversed Stroop" effect. Psychonomic Science, 28, 336-338.

Flowers, J. H., \& SToup, C. M. (1977). Selective attention between words, shapes and colors in speeded classification and vocalization tasks. Memory \& Cognition, 5, 299-307

Flowers, J. H., Warner, J. L., \& Polansky, M. L. (1979). Response and encoding factors in "ignoring" irrelevant information. Memory \& Cognition, 7, 86-94.

FraISSE, P. (1969). Why is naming longer than reading? Acta Psychologica, 30, 96-103.

GARNER, W. R. (1974a). Attention: The processing of multiple sources of information. In E. C. Carterette \& M. P. Friedman (Eds.), Handbook of perception (Vol. 2, pp. 23-59). New York: Academic Press.

GARNER, W. R. (1974b). The processing of information and structure. Potomac, MD: Erlbaum.

Garner, W. R. (1983). Asymmetric interactions of stimulus dimensions in perceptual information processing. In T. J. Tighe \& B. E. Shepp (Eds.), Perception, cognition, and development: Interactional analyses (pp. 1-37). Hillsdale, NJ: Erlbaum.

Garner, W. R., \& Felfoldy, G. L. (1970). Integrality of stimulus dimensions in various types of information processing. Cognitive Psychology, 1, 225-241.

Glaser, M. O., \& Glaser, W. R. (1982). Time course analysis of the Stroop phenomenon. Journal of Experimental Psychology: Human Perception \& Performance, 8, 875-894.

Green, D. M., \& Swets, J. A. (1966). Signal detection theory and psychophysics. New York: Wiley.

GUMENIK, W. E., \& Glass, R. (1970). Effects of reducing the readability of the words in the Stroop color-word test. Psychonomic Science, 20, 247-248.

JACOBY, L. L., \& DALlAS, M. (1981). On the relationship between autobiographical memory and perceptual leaming. Joumal of Experimental Psychology: General, 3, 306-340.

JoNIDES, J., \& YANTIS, S. (1988). Uniqueness of abrupt visual onset in capturing attention. Perception \& Psychophysics, 43, 346-354.

KEELE, S. (1972). Attention demands of memory retrieval. Joumal of Experimental Psychology, 93, 245-248.

Kemler, D. G. (1983). Holistic and analytic modes in perceptual and cognitive development. In T. Tighe \& B. E. Shepp (Eds.), Perception, cognition, and development: Interactional analyses (pp. 77-102). Hillsdale, NJ: Erlbaum.

KIRSNER, K., \& DUNN, J. (1985). The perceptual record: A common factor in repetition priming and attribute retention. In M. I. Posner \& O. S. M. Marin (Eds.), Attention and performance XI (pp. 547 565). Hillsdale, NJ: Erlbaum.

Lockhe ad, G. R. (1972). Processing dimensional stimuli: A note. Psychological Review, 79, 410-419.

LockhEAD, G. R. (1979). Holistic versus analytic process models: A reply. Joumal of Experimental Psychology: Human Perception \& Performance, 5, 746-755.

Lockhead, G. R. (1992). Psychophysical scaling: Judgments of attributes or objects? Behaviorial \& Brain Sciences, 15, 543-601.

LoGan, G. D. (1980). Attention and automaticity in Stroop and priming tasks: Theory and data. Cognitive Psychology, 12, 523-553.

LoGan, G. (1988). Toward an instance theory of automatization. Psychological Review, 95, 492-527.

MacLeOD, C. M. (1991). Half a century of research on the Stroop effect: An integrative review. Psychological Bulletin, 109, 163-203.

MacLeod, C. M., \& Dunbar, K. (1988). Training and Stroop-like interference: Evidence for a continuum of automaticity. Journal of $E_{x}$ perimental Psychology; Learning, Memory, \& Cognition, 14, 126-135.

MCCLAIN, L. (1983). Stimulus-response compatibility affects auditory Stroop interference. Perception \& Psychophysics, 33, 266-270.

Melara, R. D. (1989). Dimensional interaction between color and pitch. Journal of Experimental Psychology: Human Perception \& Performance, 15, 69-79.

Melara, R. D. (November, 1990). Mandatory processes: Consider your 
options. Paper presented at the meeting of the Psychonomic Society, New Orleans.

Melara, R. D., \& Marks, L. E. (1990a). Dimensional interactions in language processing: Investigating directions and levels of crosstalk. Journal of Experimental Psychology: Learning, Memory, \& Cognition, 16, 539-554.

Melara, R. D., \& Marks, L. E. (1990b). Perceptual primacy of dimensions: Support for a model of dimensional interaction. Journal of Experimental Psychology: Human Perception \& Performance, 16, 398-414.

Melara, R. D., \& Marks, L. E. (1990c). Processes underlying dimensional interactions: Correspondences between linguistic and nonlinguistic dimensions. Memory \& Cognition, 18, 477-495.

Melara, R. D., Marks, L. E., \& Lesko, K. E. (1992). Optional processes in similarity judgments. Perception \& Psychophysics, 51 , 123-133.

Melara, R. D., Marks, L. E., Potts, B. (in press-a). Early-holistic processing or dimensional similarity? Joumal of Experimental Psychology: Human Perception \& Performance.

Melara, R. D., Marks, L. E., \& Potrs, B. (in press-b). The primacy of dimensions in color perception. Journal of Experimental Psychology: Human Perception \& Performance.

Melara, R. D., \& NaIRNE, J. S. (1991). On the nature of interactions between the past and the present. Journal of Experimental Psychology: Learning, Memory, \& Cognition, 17, 875-894.

Morton, J., \& Chambers, S. M. (1973). Selective attention to words and colours. Quarterly Joumal of Experimental Psychology, 25, 387-397.

Nealis, P. M. (1973). The Stroop phenomenon: Some critical tests of the response competition hypothesis. Perceptual \& Motor Skills, 37, 147-153.

Palef, S. R., \& Olson, D. R. (1975). Spatial and verbal rivalry in a Stroop-like task. Canadian Journal of Psychology, 29, 201-209.

Pomerantz, J. R. (1983). Global and local precedence: Selective attention in form and motion perception. Journal of Experimental Psychology: General, 112, 515-540.

Pomerantz, J. R. (1986). Visual form perception: An overview. In E. C. Schwab \& H. C. Nusbaum (Eds.), Pattern recognition by humans and machines: Visual perception (pp. 1-30). New York: Academic Press.

Pomerantz, J. R. (1991). The structure of visual configurations: Stimulus versus subject contributions. In G. R. Lockhead \& J. R. Pomerantz (Eds.), The perception of structure: Essays in honor of Wendell $R$. Garner (pp. 195-210). Washington, DC: American Psychological Association.

Pomerantz, J. R., Pristach, E. A., \& Carson, C. E. (1989). Attention and object perception. In B. E. Shepp \& S. Ballesteros (Eds.), Object perception: Structure and process (pp. 53-89). Hillsdale, NJ: Erlbaum.

PosNer, M. I., \& SNYDER, C. R. R. (1975). Facilitation and inhibition in the processing of signals. In P. M. A. Rabbitt \& S. Dornic (Eds.), Attention and performance $V$ (pp. 669-682). London: Academic Press.

Pritchatt, D. (1968). An investigation into some of the underlying associative verbal processes of the Stroop colour effect. Quarterly Journal of Experimental Psychology, 20, 351-359.

Proctor, R. W. (1978). Sources of color-word interference in the Stroop color-naming task. Perception \& Psychophysics, 23, 413-419.

Proctor, R. W., \& ReEVE, T. G. (1990). Stimulus-response compatibility: An integrated perspective. Amsterdam: North-Holland.

ReDDING, G. M., \& GERJETS, D. A. (1977). Stroop effect: Interference and facilitation with verbal and manual responses. Perceptual \& Motor Skills, 45, 11-17.

Redding, G. M., \& Tharp, D. A. (1981). Processing line location and orientation. Journal of Experimental Psychology: Human Perception \& Performance, 7, 115-129.

ReisberG, D., Baron, J., \& Kemler, D. G. (1980). Overcoming Stroop interference: The effects of practice on distractor potency. Journal of Experimental Psychology: Human Perception \& Peformance, 6, 140-150.

RoE, W. T., Wilsoncroft, W. E., \& Griffiths, R. S. (1980). Effects of motor and verbal practice on the Stroop task. Perceptual \& Motor Skills, 50, 647-650.

Schulz, T. (1979). Components of the reaction time Stroop-task. Psychological Research, 40, 377-395.

SHEPP, B. E. (1989). On perceiving objects: Holistic versus featural properties. In B. E. Shepp \& S. Ballesteros (Eds.), Object perception: Structure and process (pp. 203-233). Hillsdale, NJ: Erlbaum.

Sichel, J. L., \& Chandler, K. A. (1969). The color-word interference test: The effects of varied color-word combinations upon verbal response latency. Journal of Psychology, 72, 219-231.

SimON, J. R., \& BERBAUM, K. (1990). Effect of conflicting cues on information processing: The "Stroop effect" vs. the "Simon effect." Acta Psychologica, 73, 159-170.

Simon, J. R., \& Sudalaimuthu, P. (1979). Effects of S-R mapping and response modality on performance in a Stroop task. Journal of Experimental Psychology: Human Perception \& Performance, 5, 179-187.

SмIтH, G. J. W. (1970). Change in degree of interference in a Strooplike test (SWT) when the incongruent combinations are mixed with congruent ones. Psychologische Forschung, 34, 95-96.

Smith, L. B., \& KemLer, D. G. (1977). Developmental trends in free classification: Evidence for a new conceptualization of perceptual development. Journal of Experimental Child Psychology, 24, 279-298.

SMITH, L. B., \& KEMLER, D. G. (1978). Levels of experienced dimensionality in children and adults. Cognitive Psychology, 10, 502-532.

STROOP, J. R. (1935). Studies of interference in serial verbal reactions. Journal of Experimental Psychology, 18, 643-662.

Treisman, A. M. (1969). Strategies and models of selective attention. Psychological Review, 76, 282-299.

Treisman, A. M., \& Gelade, G. (1980). A feature integration theory of attention. Cognitive Psychology, 12, 97-136.

VIRZI, R. A., \& EGETH, H. E. (1985). Toward a translational model of Stroop interference. Memory \& Cognition, 13, 304-319.

WALKER, P., \& SMITH, S. (1984). Stroop interference based on the synaesthetic qualities of auditory pitch. Perception, 13, 75-81.

WINER, B. J. (1971). Statistical principles in experimental design. New York: McGraw-Hill.

WooD, C. C. (1975). Auditory and phonetic levels of processing in speech perception: Neurophysiological and information-processing analyses. Journal of Experimental Psychology: Human Perception \& Performance, 1, 3-20.

WRIGHT, R. D. (1986). Amiga 1000 hardware timing and reaction-time key interfacing. Behavior Research Methods, Instruments, \& Computers, 18, 463-465.

YANTIS, S., \& JoNIDES, J. (1984). Abrupt visual onsets and selective attention: Evidence from visual search. Journal of Experimental Psychology: Human Perception \& Performance, 10, 601-621.

\section{NOTES}

1. References to the terms Stroop congruity, congruent, or incongruent, in contexts not otherwise delimited, refer to congruity relations observed in filtering tasks.

2. All correlations between speed and accuracy reported in this study are based on 24 degrees of freedom. Hence, to be significant at the .05 level (two tailed), the absolute value of the correlation coefficient must exceed .39

3. All correlations between baseline congruity and filtering congruity reported in this study are based on 12 degrees of freedom. Hence, to be significant at the .05 level (two tailed), the absolute value of the correlation coefficient must exceed .53 .

(Manuscript received August 25, 1992; revision accepted for publication March 18, 1993.) 